\title{
Understanding the Role of Interleukin-6 (IL-6) in the Joint and Beyond: A Comprehensive Review of IL-6 Inhibition for the Management of Rheumatoid Arthritis
}

Ennio G. Favalli

Received: May 5, 2020 / Published online: July 30, 2020

(C) The Author(s) 2020

\section{ABSTRACT}

Rheumatoid arthritis (RA) is a chronic, debilitating autoimmune disorder involving inflammation and progressive destruction of the joints, affecting up to $1 \%$ of the population. The majority of patients with RA have one or more comorbid conditions, the most common being cardiovascular disease, osteoporosis, and depression, the presence of which are associated with poorer clinical outcomes and lower healthrelated quality of life. RA pathogenesis is driven by a complex network of proinflammatory cells and cytokines, and of these, interleukin-6 (IL-6) plays a key role in the chronic inflammation associated with RA. Through cell signaling that can be initiated by both membrane-bound and soluble forms of its receptor, IL-6 acts both locally to promote joint inflammation and destruction, and in the circulation to mediate extra-articular manifestations of RA, including pain, fatigue, morning stiffness, anemia, and weight loss. This narrative review describes the role of IL-6 in the pathogenesis of RA, its comorbidities, and extra-articular systemic manifestations, and examines the effects of the IL-6 receptor inhibitors sarilumab and tocilizumab on clinical endpoints of RA, patient-reported outcomes, and common comorbidities and extra-articular manifestations.

Keywords: Antirheumatic

Comorbidity; C-reactive

Inflammation; Interleukin-6;

agents;

protein;

arthritis

Digital Features To view digital features for this article go to: https://doi.org/10.6084/m9.figshare.12581825.

E. G. Favalli $(\bowtie)$

Department of Rheumatology, ASST Gaetano PiniCTO Institute, University of Milan, Milan, Italy e-mail: enniofavalli@me.com 


\section{INTRODUCTION}

\section{Key Summary Points}

Interleukin-6 (IL-6) plays an important role in the development of rheumatoid arthritis (RA) disease state within the joint.

Beyond the joint, IL- 6 is also linked to extra-articular manifestations and common comorbidities in patients with RA.

Interleukin-6 receptor (IL-6R) blockade treatment with the humanized monoclonal antibody (mAb) tocilizumab, and more recently with the human $\mathrm{mAb}$ sarilumab, has been shown in clinical studies to be an important advancement for treating RA-associated disease manifestations within and beyond the joint.

The benefits of IL-6R blockade seem to extend to improvements in many of the extra-articular manifestations of the condition, such as pain, fatigue, and anemia, as well as potentially beneficial effects on certain comorbidities, such as improvements in glycemic control in patients with RA and comorbid diabetes, improvements in bone mineral density in patients with RA prone to osteoporosis, and improvements in mood disorders.

Rheumatoid arthritis (RA) is a chronic, debilitating autoimmune disorder affecting up to $1 \%$ of the population [1]. While RA is characterized by inflammation of the synovial joint tissues, it has also been linked to a variety of extra-articular systemic manifestations including pain, fatigue, morning stiffness, anemia, weight loss, and common comorbidities such as osteoporosis, cardiovascular (CV) disease (CVD), diabetes, infection, malignancies, depression, sleep disturbances, and other mood/mental disorders. The pathogenesis of RA is driven by a complex network of proinflammatory cells and cytokines, which in the past two decades have become the target of biotechnologic drugs. The expanding number of available targeted drugs in the therapeutic armamentarium of RA has progressively increased the need for predictive factors useful to drive the prescription of the right therapy for the right patients according to a personalized approach [2]. In this scenario, a better understanding of the pathways leading to disease development can be the key for population stratification according to the heterogeneous manifestations of RA in different patients [3-6].

Among the actors involved in the network of RA, interleukin-6 (IL-6) seems to be the most pleiotropic cytokine with the greatest number of downstream influences [7, 8] (major IL-6 influences are detailed in Fig. 1). This narrative review describes the role of IL- 6 in the pathogenesis of RA, and in the associated extra-articular systemic manifestations and comorbidities often observed in clinical practice, as well as the beneficial effects of the IL-6 receptor (IL-6R) blockers sarilumab and tocilizumab from the perspectives of both the physician and the patient. This article is based on previously conducted studies and does not contain any studies with human participants or animals performed by any of the authors. The peer-reviewed primary articles used as a basis for this review were obtained from PubMed or from literature reviews.

\section{IL-6 INHIBITION: WHICH OPTIONS?}

IL-6 inhibitors target either the IL-6 ligand itself or the IL-6R $[9,10]$. In contrast to the disappointing study status for the IL-6 ligand inhibitors (sirukumab, the most advanced anti-IL-6 ligand, completed phase III trials but was rejected for approval by the US Food and Drug Administration due to safety concerns, olokizumab is in phase III, clazakizumab has not progressed from phase II, and development of gerilimzumab seems to have been halted), two agents targeting IL-6R have shown impressive results in clinical studies and are now available 


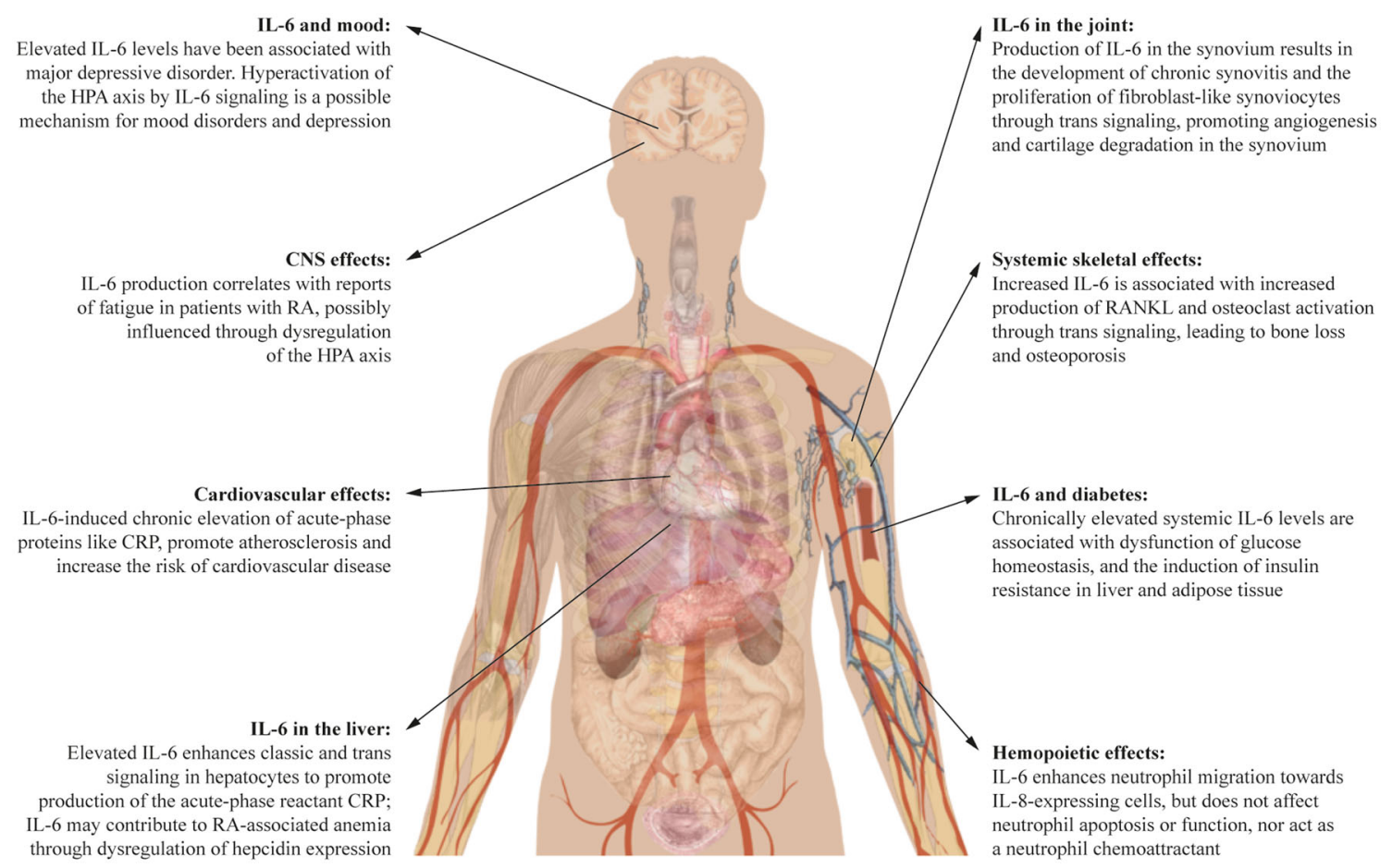

Fig. 1 IL-6 as a pleiotropic cytokine. $C N S$ central nervous system, $C R P$ C-reactive protein, $H P A$ hypothalamic-pituitary-adrenal, $I L-6$ interleukin-6, $I L-8$ interleukin-8, $R A$ rheumatoid arthritis, $R A N K L$ Receptor Activator of

clinically. Tocilizumab is a humanized monoclonal antibody (mAb) targeting IL-6R, first approved for RA as an intravenous (IV) formulation in 2009 in Europe [11] and in 2010 in the USA [12], and then approved as a subcutaneous (SC) formulation. Sarilumab is a human mAb targeting IL-6R, which was more recently approved (2017) in the USA and the EU $[13,14]$ for SC administration. Tocilizumab and sarilumab target both membrane-bound IL-6R (mIL-6R) and soluble IL-6R (sIL-6R), and both are indicated in combination with conventional synthetic disease-modifying antirheumatic drugs (csDMARDs) or as monotherapy $[9,10]$.

The recommended starting doses for tocilizumab are different in Europe and the USA $[11,12]$. In the USA, IV tocilizumab should be started at $4 \mathrm{mg} / \mathrm{kg}$ every 4 weeks (Q4W), followed by an increase to $8 \mathrm{mg} / \mathrm{kg}$ Q4W based on clinical response; SC tocilizumab should be started at $162 \mathrm{mg}$ every 2 weeks (Q2W), followed by an increase in dosing frequency to
Nuclear Factor- $\kappa B$ Ligand. Body image, Mikael Häggström https://commons.wikimedia.org/w/index.php?curid= 15298838

weekly (QW) based on clinical response (except in patients $\geq 100 \mathrm{~kg}$ who should start on the more frequent administration schedule) [12]. In Europe, IV tocilizumab should be started at $8 \mathrm{mg} / \mathrm{kg}$ body weight Q4W with a reduction of dose to $4 \mathrm{mg} / \mathrm{kg}$ for laboratory abnormalities, and SC tocilizumab should be started at $162 \mathrm{mg}$ QW with a reduction to a less frequent Q2W dosing schedule for laboratory abnormalities [11]. The recommended sarilumab dose is the same in Europe and the USA: $200 \mathrm{mg}$ Q2W administered as an SC injection, with a reduction of dose to $150 \mathrm{mg}$ Q2W recommended for the management of neutropenia, thrombocytopenia, and liver enzyme elevations $[13,14]$.

\section{Why IL-6 Blockade for RA?}

IL-6 is a soluble mediator originally cloned in 1986 [15], and subsequently named IL-6 in 1989 [16]. The effects of IL-6 are brought about by 


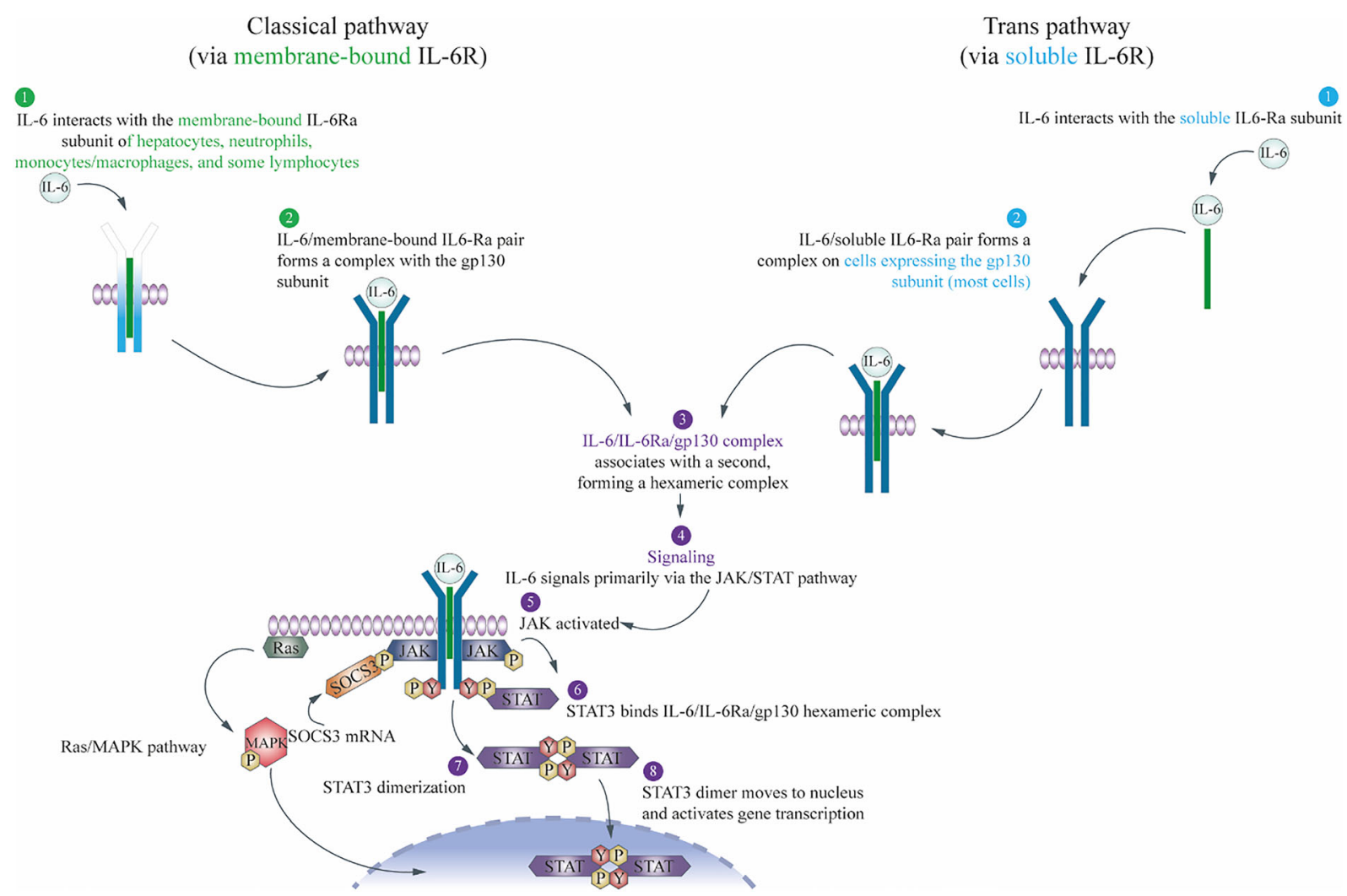

Fig. 2 The classical (or cis-) and trans-signaling pathways of IL-6. gp130 glycoprotein 130, IL-6 interleukin-6, IL$6 R \alpha$ interleukin-6 receptor alpha, $J A K$ Janus kinase,
$M A P K$ mitogen-activated protein kinase, $P$ phosphate, SOCS3 suppressor of cytokine signaling 3, STAT3 signal transducer and activator of transcription $3, Y$ tyrosine two mechanisms known as classical (or cis-) signaling and trans-signaling, as reviewed previously by many authors [17-20], and described below and in Fig. 2.

IL-6 activates cells via a signaling mechanism that requires two receptor components, an 80-kDa IL-6-binding alpha chain (IL-6R $\alpha$ ) and a 130-kDa signal-transducing beta chain, glycoprotein 130 (gp130) [17]. First, IL-6 interacts with the IL-6R $\alpha$ subunit and then this IL-6/IL$6 \mathrm{R} \alpha$ pair forms a complex with the gp130 subunit (IL-6 does not bind directly to the gp130 subunit). The high-affinity IL-6/IL-6R $\alpha /$ gp130 complex associates with a second high-affinity complex, forming a hexameric complex consisting of two members of each protein (IL-6/IL$6 \mathrm{R} \alpha / \mathrm{gp} 130$ ), which is required to induce signal transduction [18].
IL-6R $\alpha$ is expressed on only a few cell types, including hepatocytes, monocytes/macrophages, neutrophils, and some $\mathrm{T}$ cell subsets [21]. In classical signaling, IL-6 first binds to its membrane-bound receptor mIL$6 \mathrm{R} \alpha$, to form an IL-6/mIL-6R $\alpha$ pair and initiate the signaling as described above in this narrow range of cells $[19,21]$. In trans-signaling, IL-6 first forms a pair with the circulating sIL-6R $\alpha$ and this pair then forms a complex with membrane-bound gp130, which is ubiquitously expressed on many cell types. The IL-6/sIL-6R/ gp130 complex then dimerizes as described above to initiate signaling in a much wider range of cells $[19,21]$.

Activation of the receptor complex leads to signaling through Janus kinase, which binds to membrane-proximal regions of activated gp130, 
and phosphorylates specific tyrosine residues on gp130 and other target substrates, including the transcription factor signal transducer and activator of transcription 3 (STAT3) [22]. Phosphorylated STAT3 then translocates to the nucleus, and binds to specific DNA response elements and initiates the transcription of specific genes [22]. IL-6 also activates the Ras/mitogen-activated protein kinase and phosphoinositide 3-kinase/Akt pathways [23, 24].

Classical cis-signaling is thought to mediate normal homeostatic effects, while trans-signaling predominantly mediates systemic proinflammatory effects including monocyte recruitment, macrophage differentiation, and $\mathrm{T}$ cell recruitment and differentiation [19, 25]. Soluble gp130 can specifically inhibit IL-6 transsignaling by binding to the IL-6/sIL-6R pair, thus preventing the pair from binding membrane-bound gp130. During inflammation, IL-6 levels are sufficiently high to overcome this protective mechanism and trans-signaling predominates $[19,25]$.

\section{RA PATHOGENESIS: THE IMPACT OF IL-6 ON AUTOIMMUNITY AND JOINT INFLAMMATION}

In RA, under the right set of risk factors, including genetic background and environmental factors, an immune response develops, autoantibodies are generated, and self-tolerance is lost [26-28]. The first steps in the development of RA have been considered akin to the normal adaptive immune response [29]. The transition from normal immunity to the beginnings of the RA pathogenic process happens when autoimmunity occurs [28, 30, 31]. Dysregulated citrullination resulting in the autoimmune production of antibodies for citrullinated proteins is key to disease development, and is stimulated by genetic predisposition and environmental factors, such as smoking or Porphyromonas gingivalis oral infections [28].

The IL-6R is expressed on both osteoclasts and osteoblasts [22], and IL-6 is known to be a central mediator of osteoclast activity [32]. In models of early RA, in the absence of glucocorticoid treatment, IL-6 increases bone resorption, resulting in bone loss [33, 34]. IL-6 also increases osteoblast Receptor Activator of Nuclear Factor- $\kappa \mathrm{B}$ (RANK) Ligand (RANKL) production, induces RANKL messenger ribonucleic acid (mRNA) expression, and increases bone resorption through the RANK/RANKL/osteoprotegerin (OPG) interaction [35]. In addition, IL- 6 acts indirectly on bone, mediating the bone resorption-inducing effects of tumor necrosis factor $\alpha$ (TNF $\alpha$ ) and interleukin-1 (IL-1) [36]. The resulting erosion of bone and cartilage, accompanied by the inflammation and thickening of the synovial membranes, causes irreversible damage to the joint as the pannus develops [36].

From early in the disease process (preclinical RA), IL-6 binds to various cell types and causes migration of neutrophils into the joints, contributing to the subsequent transition from acute to chronic inflammation, alterations in B cell differentiation, $\mathrm{T}$ cell differentiation, and angiogenesis [37]. Circulating levels of IL-6 are normally low, but are increased in response to infection or trauma [37]. After IL-6 is synthesized in a local lesion in the initial stage of inflammation, it moves to the liver through the bloodstream and stimulates hepatocytes to produce acute-phase reactants such as C-reactive protein (CRP), a marker of systemic inflammation, fibrinogen, and serum amyloid $\mathrm{A}$ [38]. The increased production of these then leads to heightened activation of the adaptive immune system, which allows continued chronic inflammation and associated joint destruction, and is a major contributor to the advancement of RA disease pathogenesis in the joint [38].

\section{EFFECT OF SARILUMAB AND TOCILIZUMAB ON CLINICAL ENDPOINTS IN RA}

Given the pivotal role of IL-6 in the destruction of the joint, there is a strong scientific rationale for the beneficial effects observed on key endpoints as listed (Table 1) for the phase III studies of IV and SC tocilizumab, and SC sarilumab, and summarized in this section. 


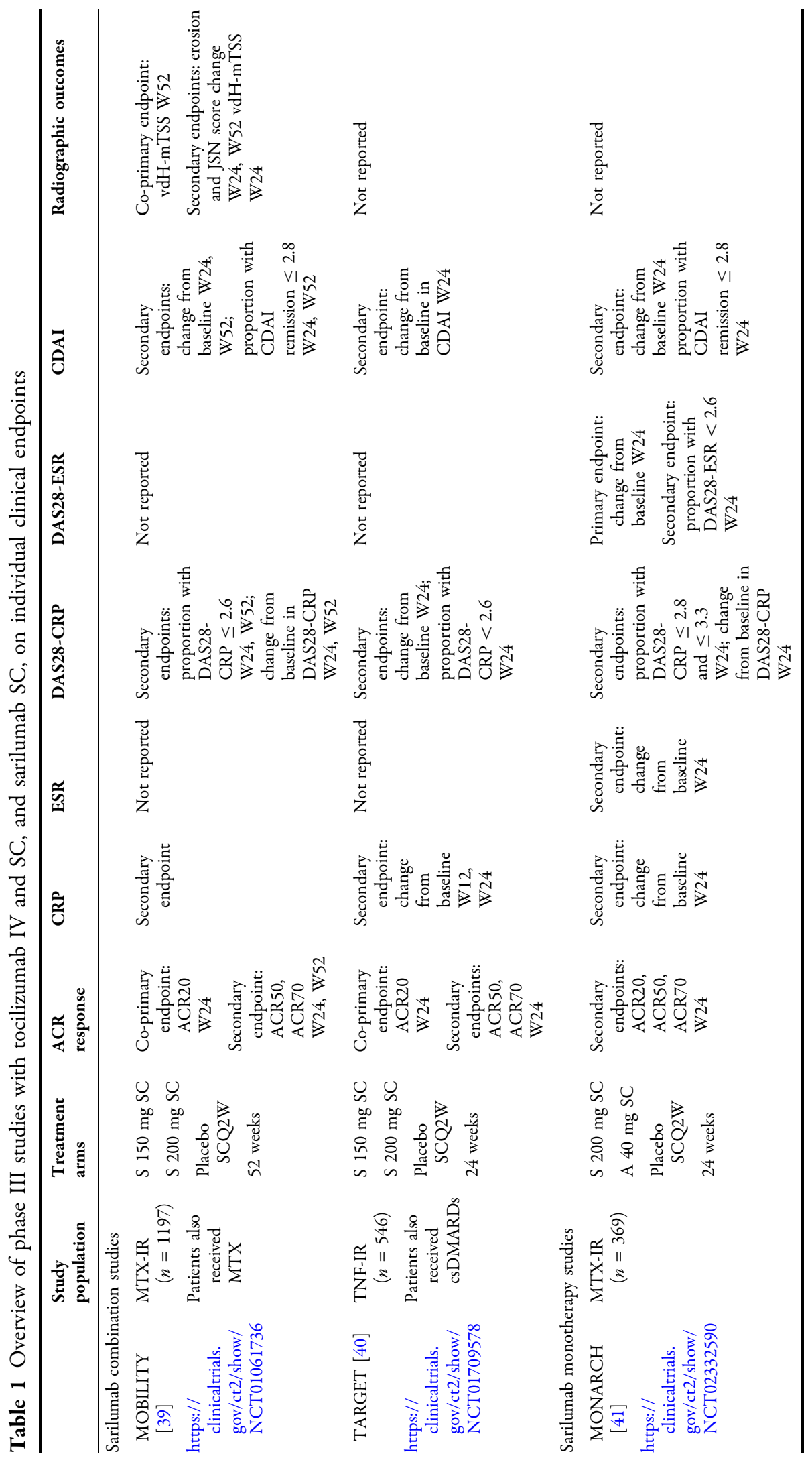




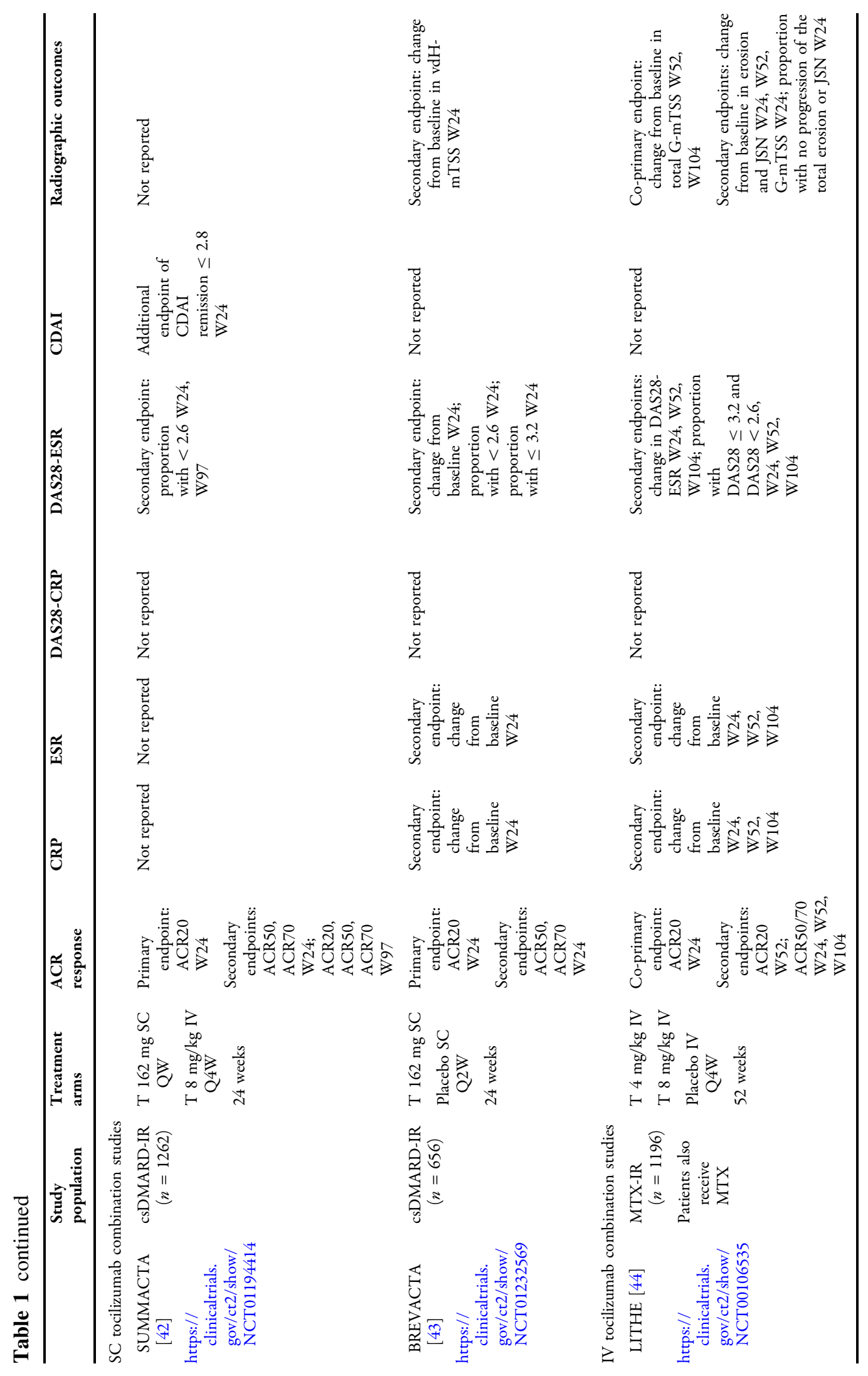




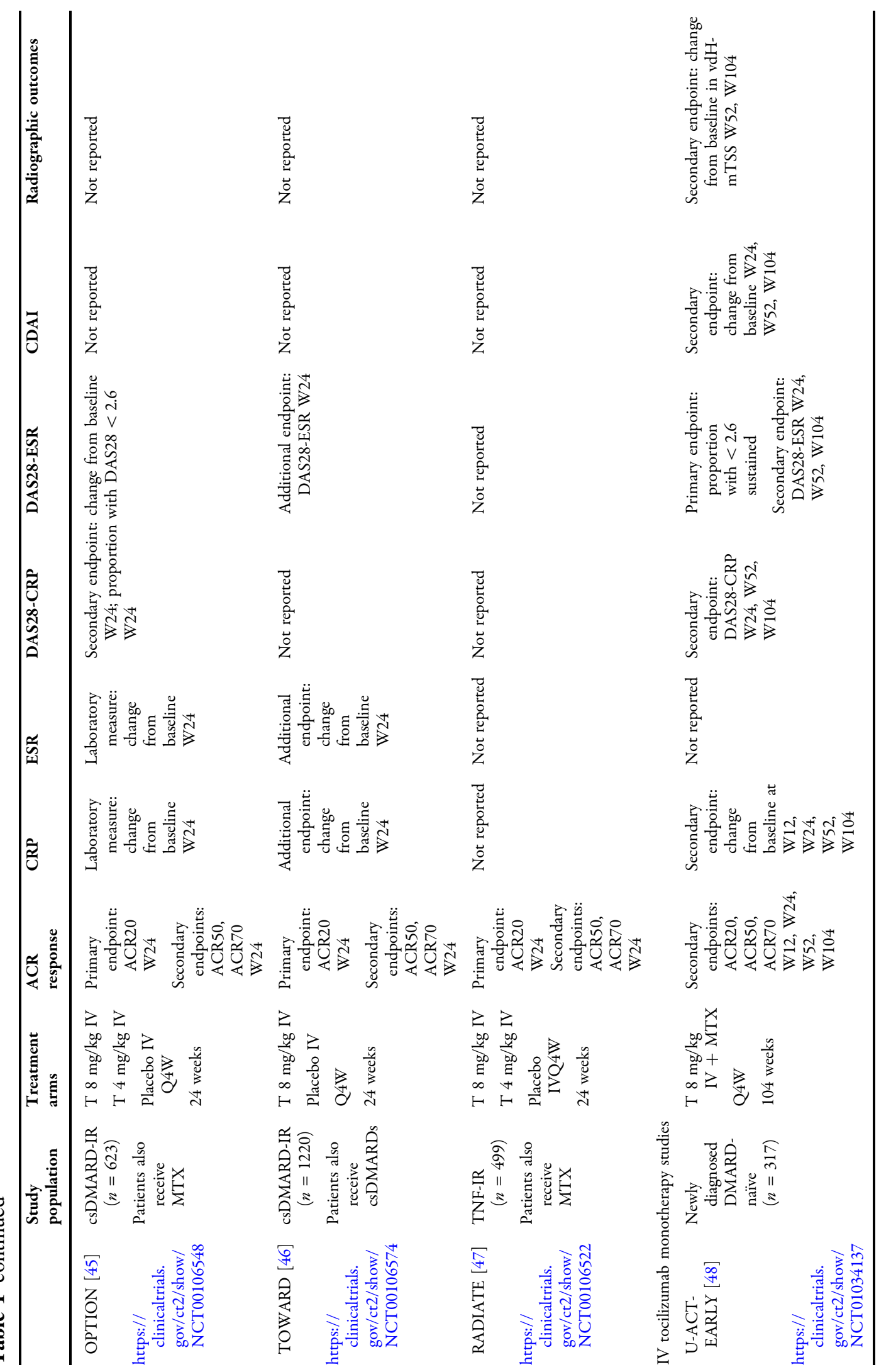




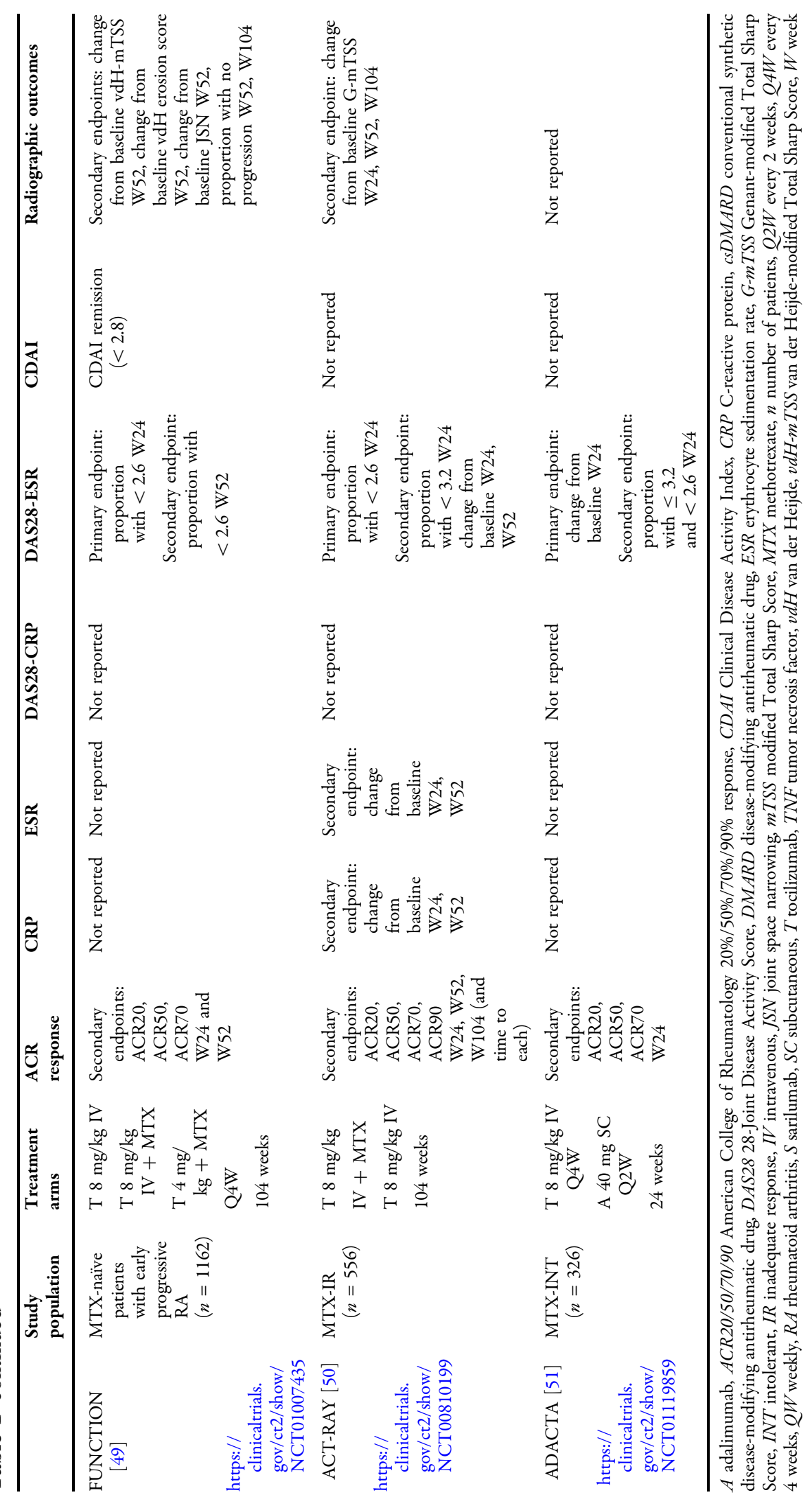


Sarilumab or Tocilizumab in Combination with csDMARDs/Methotrexate (MTX)

\section{American College of Rheumatology (ACR) Responses}

While rheumatologists agree that ACR 20\% response (ACR20) is not high, it was routinely used in the phase III trials of all licensed biologic drugs, including sarilumab and tocilizumab (Table 2) [52]. For sarilumab, ACR20 was a co-primary endpoint in both MOBILITY and TARGET. In MOBILITY, patients who had an inadequate response (IR) to MTX received SC sarilumab + MTX compared with placebo + MTX. In TARGET, patients who had IR (92.3\%) to anti-TNF $\alpha$ biologic DMARDs (bDMARDs), or who were intolerant (INT) to anti-TNF $\alpha$ bDMARDs (7.7\%), received sarilumab + csDMARDs [39, 40]. In both cases, sarilumab produced statistically significant improvements in the signs and manifestations of RA as defined by ACR20 at week 24, which was sustained throughout treatment [39, 40]. ACR20 was also the primary endpoint in SUMMACTA (which compared SC and IV tocilizumab) and BREVACTA (which compared SC tocilizumab with placebo) in csDMARD-IR populations $[43,53]$. As measured by ACR20, SC tocilizumab $162 \mathrm{mg}$ Q2W was superior to placebo [43] and SC tocilizumab $162 \mathrm{mg}$ QW demonstrated comparable efficacy to IV tocilizumab $8 \mathrm{mg} / \mathrm{kg}$ [42]. Prior to this, IV tocilizumab had shown consistent improvements in ACR20 across clinical studies, including in combination with csDMARDs in MTX-IR and TNF-IR/INT patients, and as monotherapy (Table 2) [44-47].

\section{CRP and Erythrocyte Sedimentation Rate (ESR), and 28-Joint Disease Activity Score (DAS28)-CRP and DAS28-ESR}

The acute-phase reactants, CRP and ESR, comprise one aspect of the composite ACR measure described above and, in both MOBILITY and TARGET, CRP was the acute-phase reactant evaluated, with baseline levels $20-31 \mathrm{mg} / \mathrm{l}$ across the different randomization groups $[39,40]$. In MOBILITY, mean change from baseline in CRP at week 24 was - $17 \mathrm{mg} / \mathrm{l}$ with
SC sarilumab $200 \mathrm{mg}$ Q2W [39] compared with $0.0 \mathrm{mg} / \mathrm{l}$ with placebo, and in TARGET, mean change from baseline in CRP at week 24 was $-23.3 \mathrm{mg} / \mathrm{l}$ with SC sarilumab $200 \mathrm{mg}$ Q2W compared with - 3.6 with placebo [40]. In sarilumab clinical studies, similar results with the DAS28 based on CRP (DAS28-CRP) have been observed. Changes from baseline in DAS28-CRP, and the proportions of patients achieving DAS28-CRP $<2.6$ or $<3.2$ at week 24 , were secondary endpoints of MOBILITY and TARGET $[39,40]$. In both MOBILITY and TARGET, significantly more patients treated with sarilumab achieved a DAS28-CRP score $<2.6$ at week 24 compared with patients receiving placebo (MOBILITY: 34\% with sarilumab $200 \mathrm{mg}$ Q2W compared with $10 \%$ with placebo [39]; TARGET: $29 \%$ with sarilumab $200 \mathrm{mg}$ Q2W compared with $8 \%$ with placebo [40]).

Data from the SUMMACTA and BREVACTA trials have expanded what was known from studies evaluating IV tocilizumab administration. Data showed that mean reductions from baseline in CRP and ESR were comparable for the QW SC tocilizumab 162-mg dose and Q4W IV tocilizumab $8-\mathrm{mg} / \mathrm{kg}$ regimens, but less pronounced when SC tocilizumab was administered Q2W [55]. Reductions in CRP and ESR were rapid (by week 2 or 4) and sustained through 24 and 97 weeks of treatment [55].

In BREVACTA, the proportions of patients achieving DAS28 based on ESR (DAS28-ESR) $<2.6$ by week 24 were similar with SC tocilizumab $162 \mathrm{mg}$ QW and IV tocilizumab $8 \mathrm{mg} / \mathrm{kg}$ (38\% and $36 \%$, respectively) [43], and by week 24 in SUMMACTA, $32 \%$ of patients treated with SC tocilizumab $162 \mathrm{mg}$ Q2W achieved DAS28ESR $<2.6$ (compared with $4 \%$ of patients receiving placebo) [53]. Across the previous clinical studies of IV tocilizumab, the proportion of patients achieving DAS28-ESR $<2.6$ was $28-34 \%$ in patients receiving tocilizumab compared with $1-12 \%$ of control patients at 24 weeks [44-46].

\section{Clinical Disease Activity Index (CDAI)}

Given the massive effect of IL-6 inhibition in decreasing CRP levels and the high impact of CRP in the calculation of DAS28-CRP, the CDAI is considered to be the most valuable index for 
the evaluation of the clinical response in patients treated with sarilumab or tocilizumab. Both MOBILITY and TARGET included CDAI as a secondary efficacy endpoint, evaluating the change from baseline in TARGET and the proportion of patients achieving remission $(\leq 2.8)$ in MOBILITY $[39,40]$. After 24 weeks of treatment with sarilumab $200 \mathrm{mg}$ Q2W in MOBILITY [39], 14\% of patients achieved CDAI remission (compared with $5.0 \%$ on placebo), and in TARGET [40], CDAI decreased by -26.1 (compared with - 16.4 with placebo). A 2-year update from MOBILITY showed that the initial reduction in CDAI obtained with sarilumab was maintained [56], and with 5 years of treatment, $40 \%$ of patients (observed cases) achieved CDAI remission [57].

For SC tocilizumab, CDAI was evaluated in SUMMACTA but not BREVACTA and showed, after 24 weeks of treatment, that $14-15 \%$ of patients treated with either SC or IV tocilizumab achieved CDAI $\leq 2.8$ [53]. CDAI was not routinely evaluated in the IV tocilizumab clinical program, but the results of FUNCTION showed numerically higher remission rates with IV tocilizumab compared with placebo at week 24 [49].

\section{Structural Damage}

Data on structural damage currently exist for SC sarilumab (from the MOBILITY study) and IV, but not SC, tocilizumab [39]. In the MOBILITY study (using the van der Heijde-modified Total Sharp Score [mTSS]), sarilumab was shown to have a significant effect on reducing pathologic radiographic progression compared with placebo: after 52 weeks, mean change in mTSS was 0.25 with sarilumab $200 \mathrm{mg}$ Q2W and 2.78 with placebo [39]. In a 5-year follow-up of MOBILITY [57], early treatment with sarilumab $200 \mathrm{mg}$ Q2W was associated with reduced radiographic progression versus patients who received placebo for 52 weeks and then switched to sarilumab $200 \mathrm{mg}$ Q2W (mean change from baseline in mTSS score of 1.46 vs. 3.68, respectively), and almost $50 \%$ of patients had no progression of radiographic damage (mTSS change from baseline $\leq 0$ ). Post hoc analysis of the MOBILITY clinical studies showed that patients with high IL-6 levels had more joint damage at baseline compared with patients with normal IL-6 levels, and had greater response in mTSS to sarilumab than patients with normal IL-6 levels [58].

Although radiographic progression has not been evaluated with SC tocilizumab, several studies have evaluated the effects of the IV formulation on structural damage. In the LITHE study [44], 84\% of patients had no progression of structural joint damage (defined as change in Genant-mTSS $\leq 0$ from baseline to week 52), compared with $67 \%$ of patients receiving placebo after 1 year of treatment with tocilizumab + MTX; between weeks 52 and 104, 93\% had no progression [59]. In less-established disease, the FUNCTION study showed that tocilizumab treatment for 1 year resulted in up to $83 \%$ of patients exhibiting no radiographic progression (by change from baseline in van der Heijde-mTSS), compared with 73\% with placebo, in patients with early RA of $\leq 2$ years' duration who had not previously received MTX or bDMARDs [49]. Similar results were seen in the Dutch U-ACT-EARLY study of patients with early RA of $\leq 1$ year's duration who were DMARD-naïve; radiographic joint damage progression was low in all treatment arms, but significantly less with tocilizumab + MTX than with MTX alone [48].

\section{Monotherapy with Sarilumab or Tocilizumab}

International guidelines recommend using bDMARDs in combination with csDMARDs, and as monotherapy when the combination with a csDMARD is not possible [60]. MTX is the most commonly used csDMARD and results in an ACR20 at 1 year of 54-67\% [61]; however, many MTX-treated patients complain of headaches, fatigue, feeling "wiped out," and describe an "MTX fog." Other patients experience nausea, which can be lessened by evening administration or SC rather than oral administration $[62,63]$. On MTX, patients should be closely monitored for bone marrow, liver, lung, and kidney toxicities: acute elevations of liver enzymes are frequent and acute MTX-induced lung disease may occur at any time during therapy $[62,63]$. Diarrhea and 
Table 2 Overview of the primary outcomes of the phase III studies with tocilizumab IV and SC, and sarilumab SC

\begin{tabular}{|c|c|c|}
\hline & Primary endpoint/s & Outcome \\
\hline \multicolumn{3}{|l|}{ Sarilumab combination studies } \\
\hline \multirow[t]{9}{*}{ MOBILITY [39] MTX-IR $(n=1197)$} & \multicolumn{2}{|l|}{ Co-primary endpoints: } \\
\hline & \multirow{4}{*}{ ACR20 W24 } & S $150 \mathrm{mg}$ SC: $58 \%$ ( $p<0.0001$ vs. placebo) \\
\hline & & S 200 mg SC: $66.4 \%$ ( $p<0.0001$ vs. placebo) \\
\hline & & Placebo SC: $33.4 \%$ \\
\hline & & Q2W \\
\hline & \multirow[t]{4}{*}{ vdH-mTSS W52 } & S 150 mg SC: 0.90 ( $p<0.0001$ vs. placebo) \\
\hline & & S $200 \mathrm{mg}$ SC: 0.25 ( $p<0.0001$ vs. placebo) \\
\hline & & Placebo SC: 2.78 \\
\hline & & Q2W \\
\hline \multirow[t]{9}{*}{ TARGET $[40]$ TNF-IR $(n=546)$} & \multicolumn{2}{|l|}{ Co-primary endpoints: } \\
\hline & \multirow[t]{4}{*}{ ACR20 W24 } & S 150 mg SC: $55.8 \%$ ( $p<0.0001$ vs. placebo) \\
\hline & & S 200 mg SC: $60.9 \%$ ( $p<0.0001$ vs. placebo) \\
\hline & & Placebo SC: $33.7 \%$ \\
\hline & & Q2W \\
\hline & \multirow[t]{4}{*}{ HAQ-DI change from baseline W12 } & S 150 mg SC: -0.46 ( $p=0.0007$ vs. placebo) \\
\hline & & S 200 mg SC: -0.47 ( $p=0.0004$ vs. placebo) \\
\hline & & Placebo SC: -0.26 \\
\hline & & Q2W \\
\hline \multicolumn{3}{|l|}{ Sarilumab monotherapy studies } \\
\hline \multirow{3}{*}{ MONARCH [41] MTX-IR $(n=369)$} & \multirow[t]{3}{*}{ DAS28-ESR change from baseline W24 } & S $200 \mathrm{mg}$ SC: -3.28 ( $p<0.0001$ vs. A) \\
\hline & & A 40 mg SC: -2.20 \\
\hline & & Q2W \\
\hline \multicolumn{3}{|l|}{ SC tocilizumab combination studies } \\
\hline \multirow{2}{*}{$\begin{array}{l}\text { SUMMACTA [42] csDMARD-IR } \\
(n=1262)\end{array}$} & \multirow[t]{2}{*}{ ACR20 W24 } & T 162 mg SC QW: 69.4\% \\
\hline & & T 8 mg/kg IV Q4W: 73.4\% \\
\hline \multirow[t]{3}{*}{ BREVACTA [43] csDMARD-IR $(n=656)$} & \multirow[t]{3}{*}{ ACR20 W24 } & T 162 mg SC: $60.9 \%$ ( $p<0.0001$ vs. placebo) \\
\hline & & Placebo SC: $31.5 \%$ \\
\hline & & Q2W \\
\hline \multicolumn{3}{|l|}{ IV tocilizumab combination studies } \\
\hline \multirow[t]{9}{*}{ LITHE [44] MTX-IR $(n=1196)$} & \multicolumn{2}{|l|}{ Co-primary endpoints: } \\
\hline & \multirow[t]{4}{*}{ HAQ-DI AUC change from baseline } & T 4 mg/kg IV: -128.4 ( $p<0.0001$ vs. placebo) \\
\hline & & T $8 \mathrm{mg} / \mathrm{kg}$ IV: -144.1 ( $p<0.0001$ vs. placebo) \\
\hline & & Placebo IV: - 58.1 \\
\hline & & Q4W \\
\hline & \multirow{4}{*}{$\begin{array}{l}\text { Radiographic outcome change from baseline } \\
\text { in total G-mTSS W52, W104 }\end{array}$} & T 4 mg/kg IV: 0.34 ( $p<0.0001$ vs. placebo) \\
\hline & & T 8 mg/kg IV: 0.29 ( $p<0.0001$ vs. placebo) \\
\hline & & Placebo IV: 1.13 \\
\hline & & Q4W \\
\hline \multirow[t]{4}{*}{ OPTION [45] csDMARD-IR $(n=623)$} & \multirow[t]{4}{*}{ ACR20 W24 } & T 4 mg/kg IV: $48 \%$ ( $p<0.0001$ vs. placebo) \\
\hline & & T 8 mg/kg IV: $59 \%$ ( $p<0.0001$ vs. placebo) \\
\hline & & Placebo IV: $26 \%$ \\
\hline & & Q4W \\
\hline
\end{tabular}


Table 2 continued

\begin{tabular}{|c|c|c|}
\hline & Primary endpoint/s & Outcome \\
\hline TOWARD [46] csDMARD-IR $(n=1220)$ & ACR20 W24 & $\begin{array}{l}\text { T } 8 \mathrm{mg} / \mathrm{kg} \text { IV: } 61 \%(p<0.0001 \text { vs. placebo }) \\
\text { Placebo IV: } 25 \% \\
\text { Q4W }\end{array}$ \\
\hline RADIATE [47] TNF-IR $(n=499)$ & ACR20 W24 & $\begin{array}{l}\text { T } 4 \mathrm{mg} / \mathrm{kg} \text { IV: } 30.4 \% \text { ( } p<0.001 \text { vs. placebo) } \\
\text { T } 8 \mathrm{mg} / \mathrm{kg} \text { IV: } 50 \% \text { ( } p<0.001 \text { vs. placebo }) \\
\text { Placebo IV: } 10.1 \% \\
\text { Q4W }\end{array}$ \\
\hline IV tocilizumab monotherapy studies & & \\
\hline $\begin{array}{l}\text { U-ACT-EARLY [48] Newly diagnosed } \\
\text { DMARD-naïve }(n=317)\end{array}$ & $\begin{array}{l}\text { DAS28-ESR proportion with }<2.6 \\
\text { sustained }\end{array}$ & $\begin{array}{l}\text { T } 8 \mathrm{mg} / \mathrm{kg} \text { IV }+ \text { MTX: } 86 \% \text { ( } p=0.06 \text { vs. MTX) } \\
\text { T } 8 \mathrm{mg} / \mathrm{kg} \text { IV: } 88 \%(p=0.0356 \text { vs. MTX) } \\
\text { MTX: } 77 \% \\
\text { Q4W }\end{array}$ \\
\hline $\begin{array}{l}\text { FUNCTION [54] MTX-naïve patients with } \\
\text { early progressive RA }(n=1162)\end{array}$ & DAS28-ESR proportion with $<2.6 \mathrm{~W} 24$ & $\begin{array}{l}\text { T } 4 \mathrm{mg} / \mathrm{kg}+\text { MTX: } 31.9 \%(p<0.0001 \text { vs. MTX) } \\
\text { T } 8 \mathrm{mg} / \mathrm{kg} \text { IV: } 38.7 \%(p<0.0001 \text { vs. MTX) } \\
\text { T } 8 \mathrm{mg} / \mathrm{kg} \text { IV + MTX: } 44.8 \%(p<0.0001 \text { vs. MTX) } \\
\text { MTX: } 15.0 \% \\
\text { Q4W }\end{array}$ \\
\hline ACT-RAY [50] MTX-IR $(n=556)$ & DAS28-ESR proportion with $<2.6 \mathrm{~W} 24$ & $\begin{array}{l}\text { T } 8 \text { mg/kg IV + MTX: } 40.4 \% \text { ( } p=0.19 \text { vs. T) } \\
\text { T } 8 \text { mg/kg IV: } 34.8 \%\end{array}$ \\
\hline ADACTA [51] MTX-INT $(n=326)$ & DAS28-ESR change from baseline W24 & $\begin{array}{l}\text { T } 8 \mathrm{mg} / \mathrm{kg} \text { IV Q4W: }-3.3(p<0.0001 \text { vs. A) } \\
\text { A } 40 \mathrm{mg} \mathrm{SC} \mathrm{Q2W:}-1.8\end{array}$ \\
\hline
\end{tabular}

$A$ adalimumab, ACR20 American College of Rheumatology 20\% response, $A U C$ area under the curve, $c s D M A R D$ conventional synthetic disease-modifying antirheumatic drug, DAS28 28-Joint Disease Activity Score, ESR erythrocyte sedimentation rate, G-mTSS Genant-modified Total Sharp Score, HAQ-DI Health Assessment Questionnaire-Disability Index, $I N T$ intolerant, $I R$ inadequate response, $I V$ intravenous, $m T S S$ modified Total Sharp Score, $M T X$ methotrexate, $n$ number of patients, $Q 2 W$ every 2 weeks, $Q 4 W$ every 4 weeks, $Q W$ weekly, $R A$ rheumatoid arthritis, $S$ sarilumab, $S C$ subcutaneous, $T$ tocilizumab, $T N F$ tumor necrosis factor, $v d H$ van der Heijde, $v d H$-mTSS van der Heijde-modified Total Sharp Score, $W$ week

ulcerative stomatitis require interruption of therapy to reduce the risk of hemorrhagic enteritis, and death from intestinal perforation and serious, potentially fatal opportunistic infections may occur [62-64]. Consequently, patients may discontinue MTX therapy because they cannot tolerate it $[62,63]$, while those who are able to continue MTX may not be fully adherent [65, 66]. Hence, a bDMARD monotherapy solution may be necessary. In such cases, an anti-IL-6R may be a better approach than an anti-TNF $\alpha$ therapy [60].

\section{Sarilumab Monotherapy}

The efficacy of sarilumab $200 \mathrm{mg}$ Q2W in monotherapy was assessed in the MONARCH study [41] and compared with adalimumab $40 \mathrm{mg}$ Q2W over a 24-week randomized treatment period. Sarilumab outperformed adalimumab across key endpoints: at week 24 , DAS28-
ESR was decreased - 3.28 compared with -2.20 ( $27 \%$ vs. $7 \%$ of patients achieving DAS28-ESR $\leq 2.6$ ), and more patients achieved ACR20 responses ( $71.7 \%$ vs. $58.4 \%)$ as well as ACR 50\% and $70 \%$ (ACR50/70) responses. Additionally, by week 24, the rate of CDAI remission and low disease activity (LDA) was higher in the sarilumab group ( $7 \%$ and $42 \%$, respectively) than in the adalimumab group (3\% and $25 \%$, respectively). Structural damage was not evaluated. Analysis of the open-label period of MONARCH, where patients were initially randomized to adalimumab for 24 weeks and then switched to sarilumab monotherapy, showed that (despite the improvements described above in the randomized portion of the study) adalimumab patients who switched to sarilumab achieved additional clinically meaningful improvements in disease activity primarily within 12 weeks of switching [67]. 


\section{Tocilizumab Monotherapy}

Evidence regarding the efficacy of the anti-IL-6R class was first published a decade ago, with the AMBITION study comparing IV tocilizumab $8 \mathrm{mg} / \mathrm{kg}$ Q4W to MTX over 24 weeks [68]. The study, conducted in patients with relatively early active RA for whom previous treatment with MTX or bDMARDs had not failed, showed better ACR20 response with tocilizumab (70\% vs. 53\%; $p<0.001)$ and a higher rate of DAS28-ESR $<2.6$ (34\% vs. $12 \%$ ). Subsequently, ADACTA (a comparable study to MONARCH, comparing IV tocilizumab to SC adalimumab) was published and showed the benefits of anti-IL-6R over anti-TNFa monotherapy [51]. Mean change from baseline in DAS28-ESR was - 3.3 with tocilizumab, compared with -1.8 with adalimumab after 24 weeks of treatment; $40 \%$ of patients in the tocilizumab group achieved DAS28-ESR $<2.6$, compared with $11 \%$ of patients in the adalimumab group. ACR response rates were also significantly higher with tocilizumab compared with adalimumab. The FUNCTION and U-ACT-EARLY studies also had monotherapy arms. FUNCTION [49] demonstrated that changes from baseline to week 52 in mTSS were smaller with IV tocilizumab $8 \mathrm{mg} / \mathrm{kg}$ (mean 0.26) than with MTX (1.14). U-ACT-EARLY [48] demonstrated a trend toward better protection against structural progression with IV tocilizumab compared with MTX at week 52 (change from baseline in van der Heijde-mTSS of 0.79 vs. $0.96)$ that was significant after 2 years ( 1.45 vs. 1.53). While the effects of sarilumab and tocilizumab on the clinical efficacy endpoints leading to their approvals are well established, it is the emerging effects of IL-6 and IL-6R inhibition beyond the joint that are of increasing interest and are described below.

\section{IL-6 BEYOND THE JOINT: EXTRA- ARTICULAR MANIFESTATIONS OF RA}

\section{RA and Anemia}

"Anemia of chronic disease" and "anemia of inflammation" are terms that are used interchangeably, and refer to a condition that is common in RA, being observed in $33-66 \%$ of patients with RA $[69,70]$. Clinically, patients with anemia of chronic disease are more likely to experience increased disease severity and duration than patients who have chronic disease without anemia; in patients with RA and associated anemia, disease is typically more severe, outcomes are poorer, and there is greater radiographic progression [71]. As described by Weiss and Schett in their 2013 review [72], in systemic inflammatory diseases such as RA, anemia is considered to be mainly an immunedriven disorder caused by alterations of iron homeostasis (largely mediated by hepcidin), impaired erythroid progenitor proliferation, reduced biologic activity of erythropoietin, and a decrease in erythrocyte half-life.

Hepcidin has been shown to inhibit the absorption of iron in the small intestine and the release of recycled iron from macrophages, effectively decreasing the delivery of iron to maturing erythrocytes in the bone marrow [73]. IL-6 results in increased transcription of the human antimicrobial peptide gene that encodes hepcidin in liver cells [74], and has also been shown to mediate anemia through decreasing saturation of transferrin, the primary transporter delivering iron to the bone marrow for erythropoiesis [75].

\section{IL-6R Blockade and Anemia}

Recently, a post hoc analysis showed that treatment with sarilumab resulted in larger reductions in hepcidin compared with adalimumab $(-36 \%$ compared with $-28 \%$, respectively, at week 2 , but not measured thereafter) and significantly larger increases in hemoglobin levels compared with adalimumab (least squares mean change from baseline 0.528 vs. $0.119 \mathrm{~g} / \mathrm{dl}$ at week 12 and 0.591 vs. $0.075 \mathrm{~g} / \mathrm{dl}$ at week 24 , respectively) [76]. Consequently, there were fewer patients with anemia (hemoglobin $<12 \mathrm{~g} / \mathrm{dl}$ for females or $<13 \mathrm{~g} / \mathrm{dl}$ for males) with sarilumab compared with adalimumab (10.9\% vs. $16.3 \%)$ after 24 weeks of treatment and compared with $25 \%$ of patients in both arms at baseline [76]. Furthermore, a separate analysis exploring markers of chronic inflammation in patients with RA showed larger increases in hemoglobin in patients treated with sarilumab $200 \mathrm{mg}$ and $150 \mathrm{mg}$ compared 
with placebo at week $2(68.5,64$, and $40.2 \%$ of patients with change $>0 \mathrm{~g} / \mathrm{dl}$ from baseline, respectively) that were sustained over 52 weeks (83.8, 76.6, and $44.12 \%$ of patients with change $>0 \mathrm{~g} / \mathrm{dl}$ from baseline, respectively, at week 52) [77]. Similar effects of IL-6R blockade have been shown with tocilizumab in a post hoc analysis of a placebo-controlled study [78] and in a small prospective study versus adalimumab [70].

\section{RA and Fatigue and Morning Stiffness}

Fatigue may affect up to $80 \%$ of patients with RA and is severe in up to $40 \%$ of patients $[79,80]$. Fatigue must not be mistaken for simple tiredness, since patients describe far-reaching effects permeating various aspects of life: not just physical activities, but emotions, relationships, and social activities [81]. In a small, but interesting, study of patient perspectives, most patients did not discuss fatigue with their doctors, but when they did, they felt the symptom was largely dismissed [81]. For many patients, their fatigue is "extreme" and "unresolving" [81]. Assessing fatigue in RA clinical trials was initially recommended in 2007 by the OMERACT group [82], but to this day, it is not routinely measured in interventional studies. It would be naïve to think that anemia and poor sleep, discussed elsewhere in this review, do not impact fatigue in patients with RA, but there is also increasing evidence implicating the involvement of IL- 6 and the hypothalamic-pituitary-adrenal (HPA) axis, and dysfunction of the HPA axis (particularly regarding glucocorticoid and cortisol levels) in chronic fatigue [83, 84, 85].

Morning stiffness is another common symptom of RA, with variable intensity, timing (not just associated with the morning), location, and duration [86]. Most importantly, perhaps, stiffness is frequently described as impacting patients' daily activities, including getting dressed, driving, cooking, and the ability or desire to socialize [86]. Despite its importance, morning stiffness is seldom assessed in clinical practice and usually only the duration of morning stiffness is measured in the research setting [86]. Debates concerning whether the intensity, timing, and/or location of morning stiffness should also be assessed in clinical trials are ongoing [86].

As major RA manifestations, such as joint pain and stiffness, are most pronounced in the morning, it is postulated that this may be due to circadian rhythms of cytokine and hormone levels [87]. Significant circadian variation in levels of IL- 6 has been identified: peaks in the morning, and low levels in the afternoon and evening [88]. Indeed, associations between IL-6 and the duration of morning stiffness have been identified [89].

\section{IL-6R Blockade, Fatigue, and Morning Stiffness} The positive effect of IL-6R blockade on fatigue and morning stiffness in patients with RA is described in "The importance of IL-6R blockade from a patient's perspective" section below.

\section{RA and Pain}

In RA, pain is often reported as the patient's most important symptom, and often persists despite RA control $[90,91]$. Since the pain in RA arises from multiple mechanisms, including inflammation, and peripheral and central pain processing, it also has a wide range of characteristics in terms of attributes, location, duration, and temporal occurrence [92]. Pain is also strongly associated with the patient's quality of life, including functional capacity, emotional health, and sleep [93, 94].

Neurons, glial cells of the spinal cord, and dorsal root ganglia express gp130, permitting IL-6/sIL-6R trans-signaling to occur [95]. Animal studies have shown that injections of IL- 6 or IL6/sIL-6R into normal knee joints cause increased responses of spinal neurons to mechanical stimulation [96], and a long-lasting sensitization of nociceptive C-fibers to mechanical stimuli [97]. Utilizing a rat model of antigen-induced arthritis, and soluble gp130 to bind and inactivate IL-6, Boettger et al. [98] showed antinociceptive effects in the knee joint, which were greater when administered locally than systemically, and normalized weight-bearing, gait measures, and locomotion. 
These pain-relieving effects could be achieved after a single administration of gp130 and in the absence of effects on joint inflammation. The culmination of these studies indicates that IL-6 has direct actions on the nociceptive system, and pain-relieving effects that are additional to anti-inflammatory and immunomodulatory effects.

\section{IL-6R Blockade and Pain}

The positive effect of IL-6R blockade on pain in patients with RA is described in "The importance of IL-6R blockade from a patient's perspective" section below.

\section{RA, Weight, and Body Composition}

While being overweight or obese can increase the risk of developing RA, rheumatoid cachexia (low muscle mass with or without weight loss), sarcopenia (both low muscle mass and muscle function), or sarcopenic obesity can occur in patients with RA. A recent meta-analysis showed a prevalence of rheumatoid cachexia of $15-32 \%$, according to different diagnostic criteria [99]. Utilization of dual-energy X-ray absorptiometry to evaluate visceral adipose tissue has shown that chronic, high inflammatory activity is associated with both lower muscle and fat mass (including visceral adipose tissue), while moderate inflammatory activity is associated with greater visceral adipose tissue, which is associated with increased CV risk [100].

Recent claims are that IL-6 supports healthy weight maintenance in a normal physiologic state [101], and while the causes of rheumatoid cachexia are multifactorial, the excess of proinflammatory cytokines is considered to be a central feature [102]. Anorexia and body-weight loss are common complications of inflammatory states, and IL-6, along with the proinflammatory cytokines TNF $\alpha$ and IL- $1 \beta$, has previously been found to be implicated in anorexia of inflammation and infection [103, 104]. In animal studies, IL-6 - / - mice develop spontaneous mature-onset obesity, increased body weight, SC fat, and dysregulation of glucose metabolism [105]. Furthermore, centrally administered IL-6 (into the parabrachial nuclei) reduces food intake and increases brown adipose tissue thermogenesis in lean and obese rats (by increasing thyroid and sympathetic outflow to the adipocytes), and interacts with leptin to reduce feeding [106].

\section{IL-6R Blockade and Weight}

There is some evidence of weight gain with IL6R blockade with tocilizumab [12, 107]. Tournadre et al. reported the first study of the impact of IL-6 inhibition on body composition in patients with RA [108] and showed that a gain in weight after 1 year of treatment was likely to be related to a significant increase in muscle mass, as no change in fat mass was detected, and favorable fat redistribution toward peripheral and SC fat was observed. Serum levels of leptin were significantly decreased after 6 months of tocilizumab treatment compared with pretreatment levels, and the authors suggest a proinflammatory IL-6-mediated effect on leptin, as leptin is a key regulator of appetite, inducing the expression of anorexigenic factors and inhibiting the production of orexigenic peptides. Therefore, IL-6R blockade may have utility in underweight patients with RA.

In contrast to IL-6R blockers, TNF $\alpha$ inhibitors have been shown to be associated with poor RA remission rates in obese patients with RA [109]. Gremese et al. [109] showed that disease remission according to the proportion of patients with DAS28 $<2.6$ in long-standing receivers of TNF $\alpha$ inhibitors (adalimumab, etanercept, or infliximab) was $15 \%$ in obese patients $\left(>30 \mathrm{~kg} / \mathrm{m}^{2}\right)$, compared with $>30 \%$ in patients with a nonobese body mass index (BMI) $\left(\leq 30 \mathrm{~kg} / \mathrm{m}^{2}\right)$. Increased adipose tissue in an obese state may cause increased expression of $\mathrm{TNF} \alpha$, leading to a more inflammatory and therapy-resistant state [109]. Consequently, high BMI in patients with RA is a potential driver toward treatments with mechanisms of action other than anti-TNFa, such as IL-6R blockade [109].

\section{IL-6 BEYOND THE JOINT: COMMON COMORBIDITIES OF RA}

RA can be complicated by several disorders that are more common in patients with RA than in 
the healthy population [110]. The majority of these comorbidities are deeply interconnected with RA through shared pathogenic pathways leading to chronic inflammation or to the increased presence of traditional risk factors, such as smoking [111]. Indeed, a genetic association with a non-synonymous variant of the IL-6R may underpin the pathogenic processes that connect RA and conditions such as CVD and type 1 diabetes [112] (T1D). This allele, Asp358A1a, is associated with decreased membrane-bound IL-6R and increased sIL-6R and is protective for RA, CVD, and T1D. It was demonstrated that reduced levels of IL-6R on the surface of immune cells resulted in functional impairment of classical IL-6R signaling and dampening of IL-6R-mediated inflammation. This observation supports a role for IL-6R signaling in RA beyond the inflammatory processes found in the joints, which may overlap with the pathogenic processes underpinning other diseases with an inflammatory component [112].

The impact of comorbidities on the treatment of RA can be bidirectional. In one way, the increased prevalence of comorbidities can contribute to worsening the long-term prognosis and compromising the life expectancy in patients with RA $[110,113]$. Additionally, a poorer clinical response has been observed in patients with RA carrying a great burden of comorbid disorders [114]. The most common comorbidities observed in patients with RA are osteoporosis [115], CVD [116] and pulmonary disease [117], infections [118, 119], depression [120], type 2 diabetes (T2D) [121], and malignancies [122].

\section{RA and Osteoporosis}

Osteoporosis has long been recognized as one of the most common comorbidities associated with RA $[115,123,124]$. It is prevalent in $10-50 \%$ of patients with RA depending on the population studied, and has been shown to be over twice as common in patients with RA than in age- and sex-matched controls $[115,123,124]$. The consequences of this comorbidity are important. It is well known that the use of glucocorticoids, commonly used in RA, is associated with reduced bone mineral density (BMD) due to a reduction in bone formation (rather than an increase in bone turnover) [125]; however, the risk of fracture in patients with RA is increased irrespective of glucocorticoid use [126-128].

The systemic effect of IL- 6 on bone integrity (as described above) can be considered as a manifestation of RA outside the joints. Serum levels of IL-6R are increased in osteoporosis and variants of the IL-6R gene are associated with differential BMD, supporting the link between the cytokine and the pathologic process [129-131].

\section{IL-6R Blockade, Bone Turnover, and BMD}

The effects of tocilizumab and, more recently, sarilumab on markers of bone metabolism (specifically, markers of bone formation: osteocalcin, OPG, RANKL, and N-terminal propeptide of type I collagen [P1NP]; and of bone resorption: C-terminal telopeptide of type I collagen [CTX-I] and CTX-I generated by matrix metalloproteinases [ICTP]) have been reported from randomized controlled trials. Most recently, in a monotherapy study of sarilumab versus adalimumab, after 24 weeks of treatment, blockade of IL-6R with sarilumab treatment significantly increased concentrations of P1NP and resulted in a numeric increase in osteocalcin compared with adalimumab. In addition, reductions in total RANKL compared with adalimumab were observed as early as week 2 and persisted through week 24 [132]. This was consistent with other studies that had shown that sarilumab produced an early (week 2) decrease in total RANKL levels and the soluble RANKL:OPG ratio through week 24 [133, 134]. In previous studies, tocilizumab was shown to provide overall improvement in net bone biomarker balance as measured by a $25 \%$ decrease in the CTX-I:osteocalcin ratio after 16 weeks of treatment [135], to produce small (up to 15\%) decreases in the bone degradation markers CTXI and ICTP after 24 weeks of treatment [136], and to increase osteocalcin $>100 \%$ after 52 weeks of treatment [137].

In animal models of collagen-induced arthritis, the reduction in the number of 
osteoclast precursors in bone marrow with IL-6R blockade contributes to the prevention of bone loss and protection against the reduction in bone strength [138, 139]. Clinical studies in patients with RA on the effects of IL-6R blockade on BMD have also been encouraging, although randomized trials are lacking. In several recent, but relatively small, open-label studies of patients treated with tocilizumab ( $n=76-145)$, BMD was stable over the long term and, in patients who were anti-citrullinated protein antibody-positive and/or had osteopenia at baseline, BMD increased [140-142]. In addition, considering the glucocorticoid-sparing effects of anti-IL-6R bDMARDs [143], there are various routes through which this class of agents can have beneficial effects on bone metabolism in patients with RA.

\section{RA and CVD}

CVD is the leading cause of mortality in patients with RA, and the risk of CVD is increased up to twofold in patients with RA compared with the general population $[116,144-146]$. Additionally, the use of glucocorticoids $>7.5 \mathrm{mg} /$ day or at a cumulative dose of $40 \mathrm{~g}$ is associated with a considerable increased risk of CV mortality [147]. After adjusting for traditional CV risk factors, such as hypertension, smoking, and lipid abnormalities, RA itself (or rather the high systemic inflammatory burden associated with it) is an independent risk factor for CVD [148, 149]. Furthermore, a large CV study in $>15,000$ individuals showed a clear link between CRP and CV risk [150], providing support for the central role of inflammation in the initiation and progression of atherothrombosis, and the prompting of CV events. Elevated ESR levels are also associated with increased CV risk [151].

The chronic systemic inflammatory burden in patients with RA is thought to explain, in part, what is known as the "lipid paradox": the phenomenon where patients with RA are at an increased risk of CVD and associated mortality, despite lower levels of total cholesterol or lowdensity lipoprotein cholesterol (LDL-C), or the ratio of total:high-density lipoprotein cholesterol (HDL-C), which would traditionally be considered to indicate low risk [151]. High levels of lipoprotein(a) (Lp(a)), which is atherogenic in nature, have also been reported in patients with RA [152].

The mechanisms by which inflammation confounds the association of cholesterol and CVD remain somewhat unclear, but are likely due to a myriad of factors. Given that increased CRP and ESR levels are linked to increased CVD rates, and the hepatic synthesis of CRP is largely regulated by IL-6, the direct and indirect links between IL-6 and CVD are clear, particularly in patients with inflammatory conditions such as RA. Adipose tissue is one of the main sources of inflammatory mediators, including IL- 6 , and animal studies have suggested that adipose tissue-derived IL-6 may affect adipose tissuespecific gene expression, suppressing total adiponectin release from human adipocytes [153], triglyceride release [154], and lipoprotein lipase activity [155]. It has also been shown in humans that coronary calcification mediated by IL- 6 also contributes to the development of atherosclerosis [156]. Therefore, it is unsurprising that, in a large meta-analysis, elevated IL- 6 was associated with an increased risk of coronary heart disease after adjusting for several classic vascular risk factors and correcting for within-person variability [157]. In another meta-analysis, the presence of an IL-6R variant (Asp358Ala), with effects consistent with IL-6R blockade, conferred a decreased risk of coronary heart disease [158].

\section{IL-6R Blockade, Lipid Levels, CV Risk, and Events}

The IL-6R blockers are of interest with respect to CVD risk because of their observed effects on lipid profiles in phase III studies. Across phase III studies, both sarilumab and tocilizumab treatment was associated with increases in total cholesterol, LDL-C, and HDL-C (whereas the HDL:LDL ratio remained generally stable). Consequently, prescribing guidelines recommend that physicians assess lipid parameters 4-8 weeks following initiation of treatment with IL-6R, and at regular intervals thereafter.

A recent analysis of the phase III MONARCH study, which compared the effects of sarilumab 
with the anti-TNF $\alpha$ bDMARD adalimumab, showed significantly greater reductions in Lp(a) after 24 weeks of treatment with sarilumab compared with adalimumab, and normalization of $\operatorname{Lp}(\mathrm{a})$ occurred in a numerically greater percentage of patients treated with sarilumab [132]. In a much smaller study, inhibition of IL-6 signaling with tocilizumab decreased $L p(a)$ serum levels, indicating a beneficial effect of IL-6R blockade on CV risk [159]. Other small studies have shown that IL-6R blockade improves endothelial function and/or reduces arterial stiffness $[160,161]$.

Because of the effects of tocilizumab on lipid levels, and because it was the first anti-IL-6R bDMARD, regulatory authorities requested a phase IV trial comparing the CV safety of tocilizumab with an anti-TNF $\alpha$ bDMARD in patients with RA [162]. The study, with a follow-up period of 3.2 years, showed that tocilizumab did not increase the rate of major CV events compared with etanercept (hazard ratio 1:1). This finding is consistent with the integrated safety analyses of the phase III studies of both anti-IL6R bDMARDs. Fleischmann et al. [163] recently published a report with 9000 years of patient exposure to sarilumab, which showed that the exposure-adjusted incidences of major $\mathrm{CV}$ events with sarilumab combination and monotherapy (0.5 and $0.2 / 100$ patient-years $[\mathrm{PY}]$, respectively) were no greater than those reported in the general RA population. Similar reports have been shown previously with tocilizumab [164].

\section{RA, Diabetes, and the Metabolic Syndrome}

The incidence of T2D is at least twice that in patients with RA compared with the general population, and there is an increased risk for CVD in patients with both conditions relative to patients with either RA or T2D alone $[121,165]$. The coexistence of RA and T1D is less common than that of RA and T2D (Bao et al. [166] reported that $2 \%$ of $>150,000$ patients with T1D in the USA have RA), but the risk of more than one autoimmune disease in the same patient is an established phenomenon.
Elevated circulating levels of IL-6 have been associated with dysfunctional glucose metabolism, and the induction of insulin resistance in the hepatocytes and adipocytes of obese patients with and without T2D [167, 168]. Furthermore, increased levels of IL- 6 have been associated with increased risk for the development of T2D [169, 170]. Additionally, pharmacologic management of T2D and RA can be complicated by the potential effects of RA treatments on glucose levels. In particular, oral glucocorticoids (especially higher doses and longer treatment durations) increase the risk for T2D [171].

While T2D is associated with insulin resistance, T1D is characterized by insulin deficiency caused by immune-mediated selective destruction of beta cells in the islets of Langerhans. T1D can therefore be considered an inflammatory disease of the pancreatic islets, in which beta cell apoptosis results through the interaction of activated $\mathrm{T}$ cells and proinflammatory cytokines in the immune infiltrate [172]. In vitro and in vivo research in animals has implicated IL-6 in T1D, identifying that, in addition to a possible role in regulating pancreatic beta cell function (inhibiting glucosestimulated insulin secretion from pancreatic islets), IL-6 produced by pancreatic beta cells may act as a co-stimulator for autoreactive B and T lymphocytes in T1D [173, 174].

\section{IL-6R Blockade, Insulin Sensitivity, and Glycosylated Hemoglobin}

In recent post hoc analyses, the decreases in hemoglobin A1c (HbA1c) were greater in sarilumab groups than placebo or adalimumab groups at week $24(n=20)$ among patients with RA, both without and with T2D, as identified by medical history or use of antidiabetic medication [175]. Similar reductions in HbA1c were shown in a small open-label study of patients with active RA ( $n=10$ with T2D and HbA1c $\geq 6.4 \%$ ) treated with IV tocilizumab $8 \mathrm{mg} / \mathrm{kg}$ Q4W for 24 weeks [176], and in an observational study where tocilizumab decreased HbA1c levels in patients with RA to a greater extent than anti-TNF $\alpha$ bDMARDs [177]. Tocilizumab has also been shown to improve insulin sensitivity as determined by the Homeostatic 
Model Assessment of Insulin Resistance (HOMA-IR) index and the leptin:adiponectin ratio in non-diabetic patients with rheumatoid disease [159].

To date, there are limited data on the effects of IL-6R blockade in patients with T1D, but the results of a clinical trial to assess the potential efficacy of anti-IL-6 therapy on beta cell responses in children and adolescents with newonset T1D are awaited with interest (https:// www.extendstudy.org/about-extend).

\section{RA and Mood and Sleep Disturbances}

Many patients with RA suffer from mood disorders, particularly depression and anxiety [120]. A meta-analysis of 72 studies in $>13,000$ patients with RA found the prevalence of depression to be $38 \%$ [120], and despite the clinical focus on depression among people with arthritis, anxiety can be more common than depression [178]. In RA, mood disorders are associated with pain, disability, and impaired quality of life, and can even adversely affect adherence to therapy $[93,179,180]$.

Although the link between mood disorders and RA is certainly multifactorial, evidence points toward IL- 6 being one of these key factors. Dowlati et al. [181] performed a metaanalysis that showed significantly higher serum concentrations of TNF $\alpha$ and IL- 6 in patients with major depression compared with control subjects. An updated meta-analysis by Haapakoski et al. [182] continued to show higher mean levels of IL-6 in patients with major depression compared with non-depressed controls, but found that the association between $\mathrm{TNF} \alpha$ and risk of depression was uncertain due to heterogeneity in study-specific estimates and inconsistencies between subgroups. In healthy individuals, low serum levels of IL-6 predict earlier resolution of negative mood following psychosocial distress, and administration of IL-6 results in significantly depressed self-reported $\operatorname{mood}[183,184]$. A "low-IL-6" synthesizing genotype associated with lower levels of depression has also been identified [185], and animal studies have shown that IL-6R blockade can induce long-lasting antidepressant effects in susceptible mice after social-defeat stress [186].

The HPA axis is the major endocrine system regulating the physiologic response to stress, and although the mechanisms by which IL-6 affects mood have not been fully elucidated, effects on the HPA axis have been implicated [187, 188]. Positive temporal correlations between plasma levels of IL-6 and HPA hormones, adrenocorticotropic hormone, and cortisol have been demonstrated [187, 188]. Given that dysregulation of the HPA axis has been associated with both depressive and anxiety disorders in RA and other conditions, such as cancer [188, 189], the IL-6-HPA axis interaction is a plausible explanation for the clinical effects on mood that are seen.

Another prevalent complaint of patients with RA is poor sleep quality, which has been associated with depression, pain, fatigue, and functional disability [190, 191]. Polysomnographic studies have also confirmed that chronic pain is associated with poor sleep continuity and reduced total sleep time in other populations, although it is also hypothesized that sleep disturbance might drive RA-related pain [192].

In healthy subjects, elevated IL-6 is negatively correlated with sleep quality and positively correlated with ineffective interrupted sleep [190, 191]. IL-6 is also involved in normal sleep regulation. In healthy individuals, quantity of sleep correlates negatively with the overall daytime secretion of IL-6, and individuals deprived of sleep have daytime oversecretion of IL-6 [193]. SC administration of IL-6 into healthy individuals significantly alters sleep structure, and promotes manifestations of somnolence and fatigue [183, 193]. Research has implicated the link between IL- 6 and the HPA axis in poor sleep; IL-6-induced HPA axis activation in patients with RA results in transient hypercortisolemia during the early hours of sleep, which may explain the poor sleep quality during this period [194].

\section{IL-6R Blockade and Effects on Mood Disorders and Sleep}

In patients with RA, IL-6R blockade with tocilizumab and sarilumab has previously been 
reported to be associated with improvements in sleep. Most recently, in a subanalysis of Italian data from the TOZURA multicenter phase IIIb/ IV trial, Bazzichi et al. [195] reported a significant improvement in sleep quality after 24 (but not 12) weeks of tocilizumab treatment using the Pittsburgh Sleep Quality Index questionnaire. Previously, Strand et al. [196] reported a clinically significant improvement in sleep after 24 weeks of sarilumab treatment using a sleep visual analog scale (VAS), with a decrease in score of -16.9 from a baseline of 54.1.

Evidence indicating that IL-6R blockers have positive effects on mood in patients with RA is discussed in more detail in "The importance of IL-6R blockade from a patient's perspective" section below.

\section{RA and Infections}

Disease activity associated with RA is a risk factor for infection explained by the pathobiologic immune system disturbances of RA itself, the impact of chronic comorbid conditions, and sequelae of immunosuppressive treatment. Individuals with RA have a twofold increased adjusted risk of hospitalized infection compared with those without, an observation that was first identified over 50 years ago and has been confirmed in recent years $[118,119]$. Upper and lower respiratory tract infections are often the most common infections, and a history of serious infections and/or comorbidities, increased glucocorticoid dose, and older age are important risk factors of serious infections in patients treated with bDMARDs.

The risk of serious infections with bDMARDs targeting TNF $\alpha$ is higher compared with the use of csDMARDs, particularly during the first 6 months of treatment [197-199], and the addition of MTX to bDMARDs does not appear to increase the risk of serious infection [200]. However, it is interesting to note that the risk of sepsis or mortality may be lower in patients exposed to bDMARDs compared with csDMARDs at the time of serious infection [201], which suggests that successful immunosuppression may prevent the unregulated host response to serious infection. Further research is obviously warranted, but such findings highlight the complexity of the mechanisms involved in immunomodulation and infection.

\section{IL-6R Blockade and Infection in RA}

Given the increased infection risk with other bDMARDs, and since IL- 6 has a pivotal role in the recruitment and antiapoptosis of $\mathrm{T}$ lymphocytes, and in $\mathrm{B}$ and $\mathrm{T}$ cell differentiation, the impact of IL-6R blockade on the risk of infections is of considerable interest. In the clinical studies MOBILITY, TARGET, and MONARCH, and in the recently published integrated safety analysis of 2887 patients receiving sarilumab in combination with csDMARDs or as monotherapy (8188 and 812 PY, respectively), the risk of infections was found to be increased compared with placebo but in line with other bDMARDs [39-41, 163]. IL-6 blockade with tocilizumab and sarilumab has been shown to cause a decrease in neutrophil levels [163, 202-204]. However, the reduction in absolute neutrophil count (ANC) observed with sarilumab is not associated with an increased risk of infection or serious infection in clinical studies, and a "margination" hypothesis has been described to explain these observations [205] (discussed further in the "Safety and tolerability of IL-6 blockade" section of this article).

\section{RA and Malignancy}

The association between RA and cancer has been a clinical concern, and focus of research efforts, since links between RA and cancer (as well as between RA treatments and cancer) were first identified. Epidemiologic studies have generally demonstrated that hematopoietic, lung, and skin cancers can be increased in patients with RA, while breast and colon cancers are decreased, and that there is a very slight overall increase in all cancers [206-208]. There have been various hypotheses for the differences in the increased risk of certain malignancies in patients with RA. Inflammatory responses play pivotal roles in cancer development, including tumor initiation, promotion, progression, and metastasis [122]. Inflammation is believed to play a key role in the risk of 
lymphoma in particular, and evidence suggests that it is the disease activity associated with RA that confers the risk of lymphoma [122].

IL-6 is highly upregulated in many cancers, and considered one of the most important cytokines associated with tumorigenesis and metastasis [209]. A high serum concentration of IL-6 is a prognostic indicator of poor outcome in patients with various cancers, including gastric, pancreatic, melanoma, breast, colorectal, myeloma, and lung cancers [209]. As well as acting directly on tumor cells, IL-6 can act on other cells within the complex tumor microenvironment to sustain a protumor setting, and acting through STAT3, IL-6 also supports tumor cell survival [210]. The role of IL-6 signaling in the activation of downstream pathways in cancer has been reviewed extensively [211-215] and is therefore not further expanded here.

\section{IL-6R Blockade and Malignancy in RA}

Unlike some other DMARDs used to treat RA, the prescribing information for IL-6R blockers does not have a warning regarding malignancies [11-14]. It is acknowledged that malignancies have been reported in clinical studies, but analyses indicate that IL-6 blockade with sarilumab and tocilizumab does not increase cancer risk significantly compared with treatmentnaïve groups $[163,164,216]$. The overall rates of malignancy of $0.7 / 100 \mathrm{PY}$ for sarilumab combination therapy, $0.6 / 100$ PY for sarilumab monotherapy [163], and 1.1-1.2/100 PY with tocilizumab $[164,216]$ are comparable with the rate of $1.3 / 100$ PY observed in a contemporary large US cohort of patients with RA $(>40,000$ PY), in which $>60 \%$ of patients were treated with anti-TNF $\alpha$ bDMARDs [217].

\section{RA and Interstitial Lung Disease}

Interstitial lung disease (ILD) is the most common pulmonary complication in patients with RA, with a reported lifetime risk of developing ILD of $7.7 \%$ for patients with RA compared with $0.9 \%$ for those without RA. [117] There has been growing interest in the overlap of these two conditions in recent years, particularly since prognosis is so poor, with a mean of 2.6 years' survival after diagnosis [117]. Indeed, certain drugs used to treat RA, such as MTX and potentially (although data are conflicting) antiTNF $\alpha$ bDMARDs, have been associated with the development or progression of ILD [117].

A recent report has shown that active RA is associated with an increased risk for developing RA-ILD, with a hazard ratio of 2.22 for patients with moderate/high disease activity compared with those with LDA or in remission [218], thus providing the link with systemic inflammation, of which IL-6 is a key driver. However, while elevated levels of serum IL-6 (> $7.67 \mathrm{pg} / \mathrm{ml})$ have been shown to be predictive of negative outcomes in ILD associated with systemic sclerosis (SSc-ILD) [219], and elevated serum interleukin-18 levels have recently been shown to be associated with the presence of ILD in patients with RA [220], there is a paucity of research investigating the role of IL-6 in RA-ILD [221, 222].

\section{IL-6R Blockade and ILD}

Although primary endpoints were not met in the phase II faSScinate [223] and phase III focuSSced trials conducted in patients with SScILD, there was some evidence of reduced lung function decline with the anti-IL-6R agent tocilizumab. In addition, case series have also reported modest effects in patients with SScILD, with approximately $50 \%$ of patients achieving an improvement or stabilization of pulmonary function [224]. However, to date there is limited information on the effects of IL6 blockade on ILD in patients with RA, with evidence limited to case reports describing anecdotal benefits regarding the off-label use of tocilizumab in patients with RA and ILD [225-227].

\section{THE IMPORTANCE OF IL-6R BLOCKADE FROM A PATIENT'S PERSPECTIVE}

While the clinical endpoints (discussed in the "Effect of sarilumab and tocilizumab on clinical endpoints in RA" section above) are valuable 
from a clinical perspective and help guide treatment decisions, they are of little direct relevance to patients themselves. In fact, RA is no different from other conditions in that there is often a disconnect between the treatment goals of patients and those of their physicians. In surveys conducted between 2014 and 2016, of approximately 1800 patients with RA whose RA was primarily managed by a rheumatologist and a similar number of physicians managing patients with RA, while $90 \%$ of physicians were satisfied with their communication with their patients regarding RA treatment, $61 \%$ of patients felt uncomfortable raising concerns or fears with their physician [228]. Over one-half of patients responding felt that improved dialogue/discussion with their physician would optimize their RA management, and over twothirds of physicians wished that they and their patients talked more about RA goals and treatment [228]. The European League Against Rheumatism (EULAR) 2016 RA treatment recommendations were designed, in part, based on recognition of a need for improved dialogue surrounding RA manifestations [60], such as is reported here. As such, the first overarching principle is that best care for patients must be aimed for, and that such care should be based on shared decisions made between the patient and their rheumatologist [60].

Indeed, factors influencing treatment decisions differ between rheumatologists and patients [229]. Physicians are more likely to escalate treatment based on DAS28 scores, the number of swollen joints, levels of CRP, and progression of joint erosion, while patients rate the number of painful joints, fatigue, morning stiffness, and level of physical function as more important factors [230]. A recent review of patient perspectives also highlighted routes of administration as an important attribute influencing treatment preferences [231]. Studies have documented a preference for newer autoinjectors over prefilled syringes, consistent with high satisfaction rates with the sarilumab autoinjector pen [232].

Table 3 lists the key phase III studies for IV and SC tocilizumab, SC sarilumab, and patientreported outcomes investigated [233], and the following sections describe how these measures provide more information on the beneficial effects of anti-IL-6R bDMARDs on some of the comorbid conditions and extra-articular manifestations associated with RA.

\section{Combination Therapy with Sarilumab and Tocilizumab}

\section{Physical Functioning}

The Health Assessment Questionnaire Disability Index (HAQ-DI) is often the measure used to assess the physical disability component of the ACR core set and, for sarilumab, was evaluated in MOBILITY at week 16 [39] and TARGET at week 12 [40], with change from baseline included as co-primary endpoints (Table 2). In the MOBILITY study, significant improvement was observed at weeks 16 , 24 , and 52 of the study, and in the TARGET clinical study, the mean change in HAQ-DI score after week 12 of the study was significantly increased versus the placebo groups $[39,40]$. Treatment with tocilizumab has also been found to cause improvements in HAQ-DI scores. In the SUMMACTA study, mean HAQ-DI score improvements with SC tocilizumab were observed to be maintained at approximately - 0.6 compared with baseline values from week 24 through to week 97 [53]. In the LITHE study, the proportion of patients receiving treatment who maintained a HAQ-DI improvement score of $\geq 0.3$ from the baseline level to week 24 of the study was numerically higher with IV tocilizumab than in the untreated control group [44]. At week 24 in the TOWARD study [46], $60 \%$ of treated patients were reported to exhibit clinically meaningful HAQ-DI score improvements compared with 34\% in the untreated control group, with baseline mean change also significantly greater in the tocilizumab-treated versus the control group. The RADIATE study reported that HAQ-DI values improved by -0.31 and 0.39 (tocilizumab $4 \mathrm{mg}$ / $\mathrm{kg}$ and $8 \mathrm{mg} / \mathrm{kg}$ doses, respectively) versus -0.05 in treated compared with control groups [47].

\section{Effects of Sarilumab and Tocilizumab on Mood and Depressive Manifestations}

In post hoc analyses, approximately $60 \%$ of patients enrolled into MOBILITY and TARGET were classified at baseline as having probable 


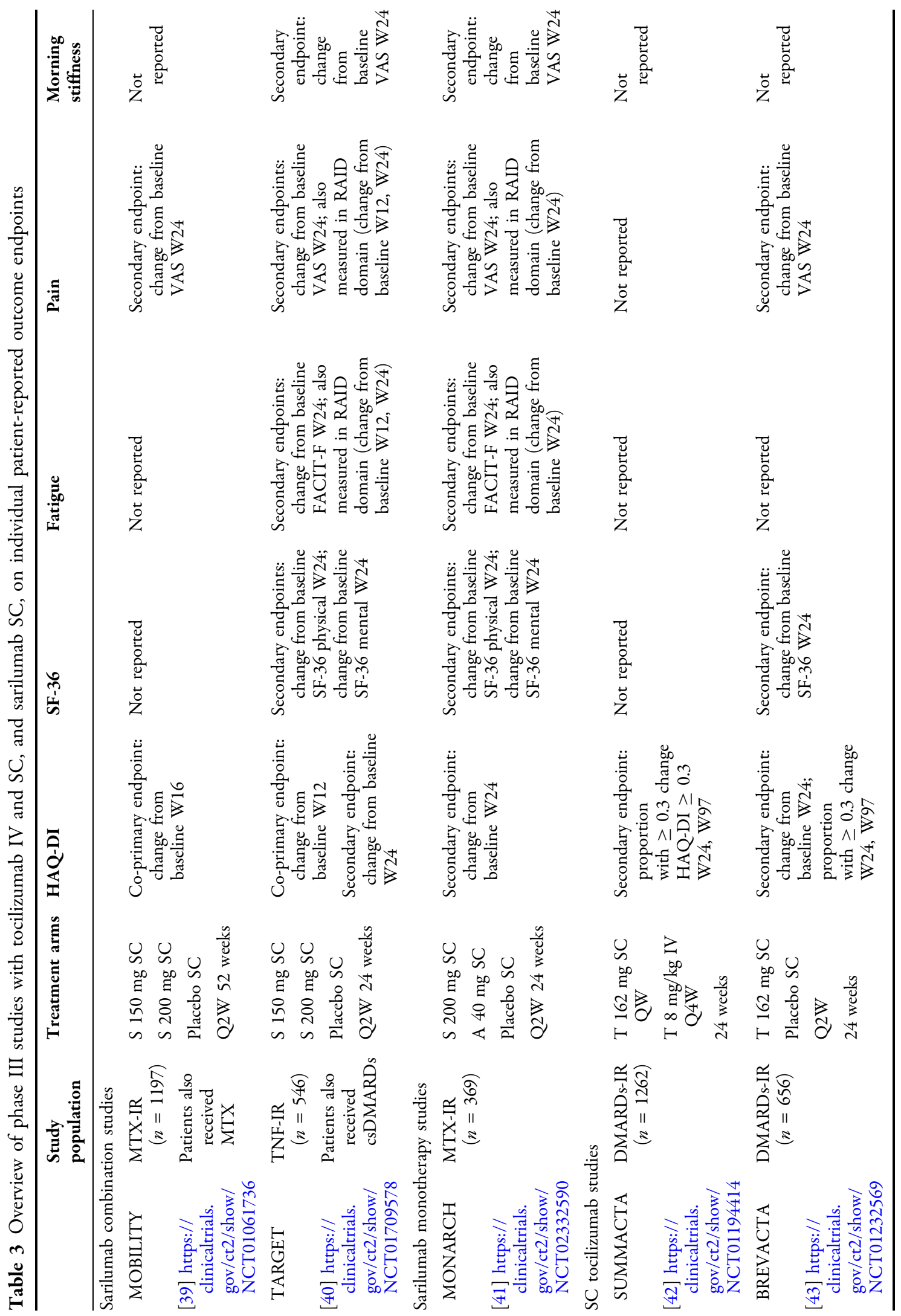




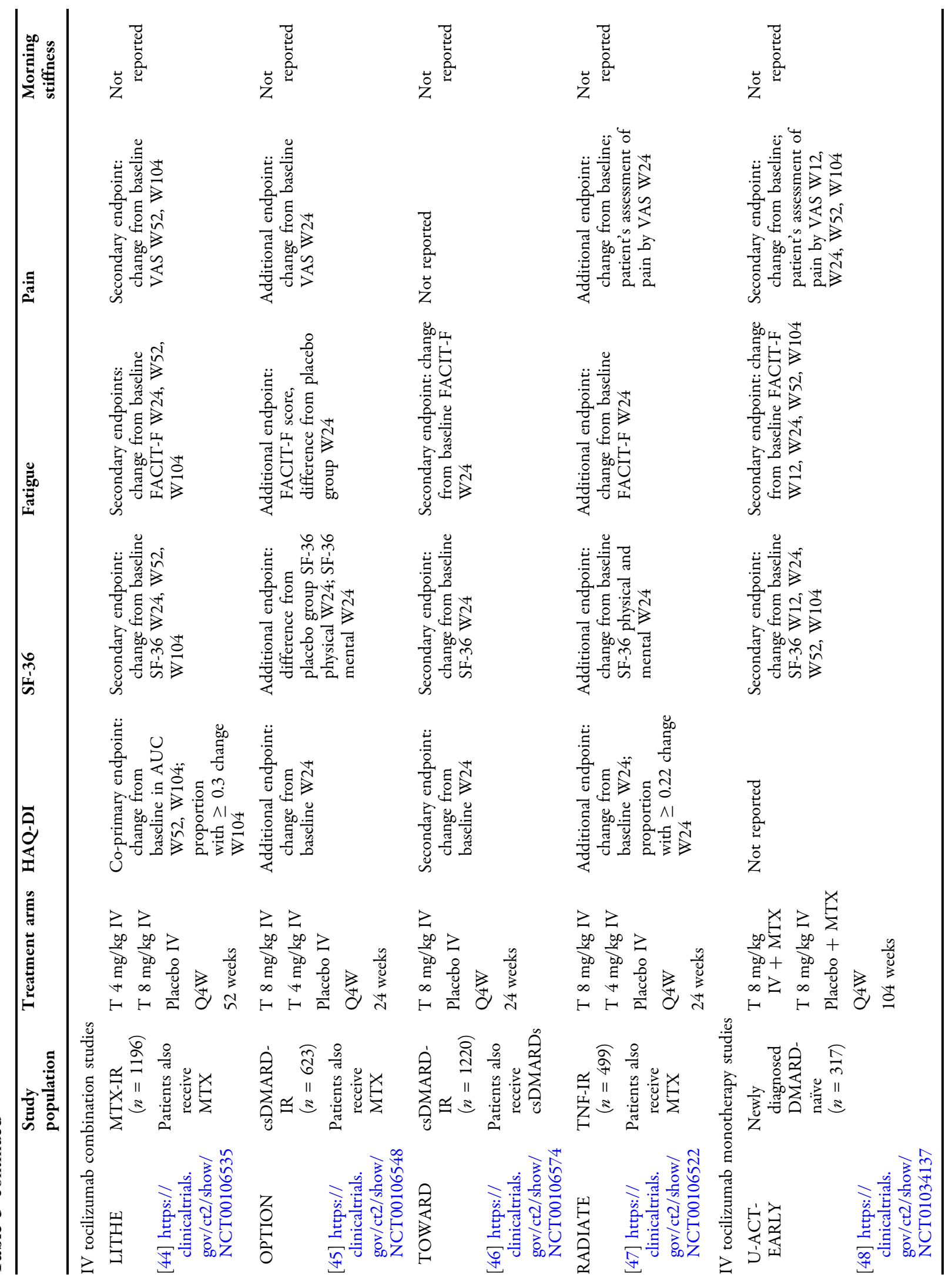




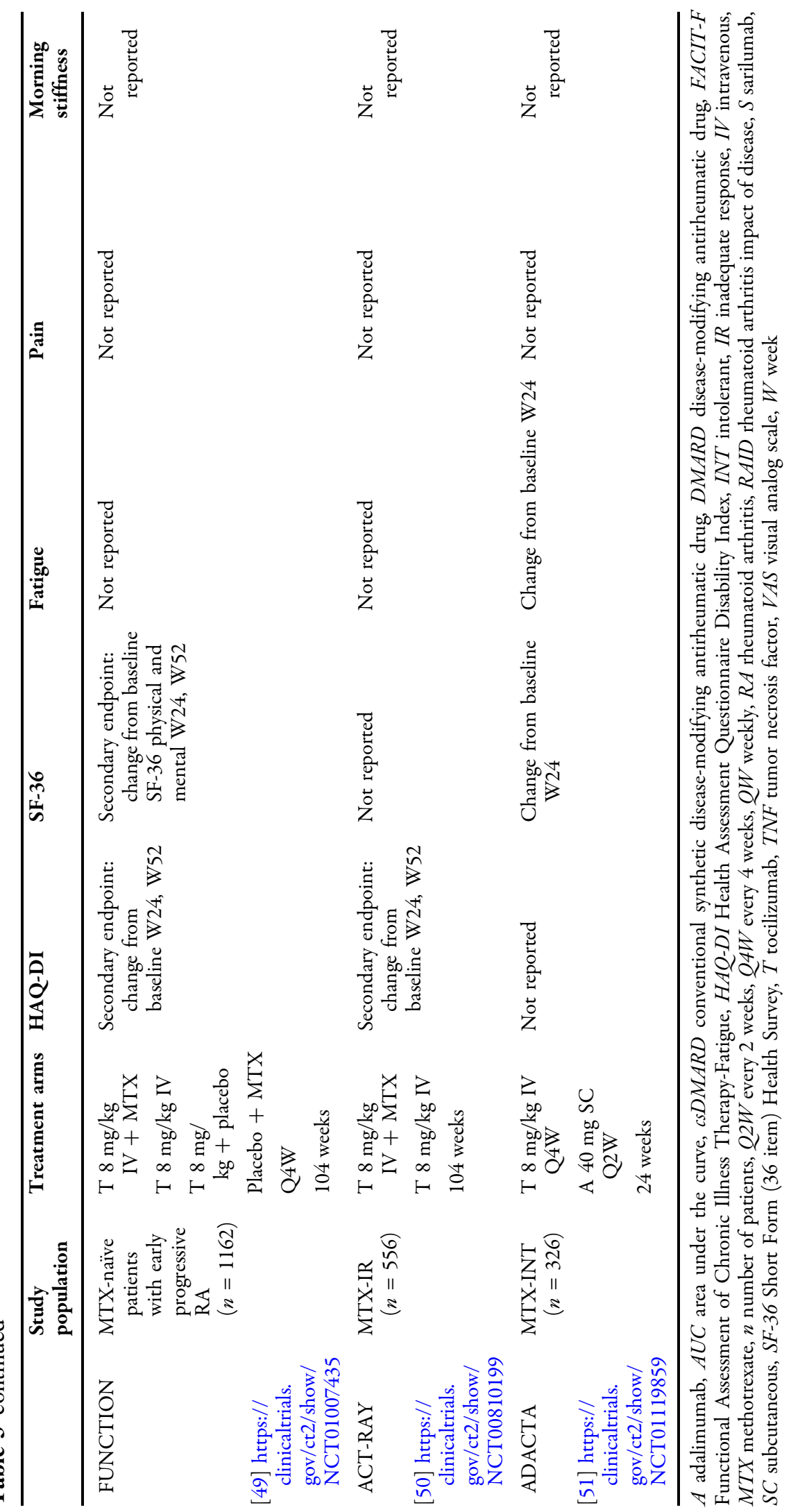


major depressive disorder (PMDD; according to the Short Form [36-item] Health Survey [SF-36] mental health $[\mathrm{MH}]$ domain score $\leq 56$ ), and approximately $50 \%$ were classified as having probable depressed mood and anhedonia (PDMA; score $\leq 10$ on both items of the $\mathrm{MH}$ domain: "Have you felt downhearted and depressed?" and "Have you felt so down in the dumps that nothing could cheer you up?"). In both studies, sarilumab provided clinically meaningful improvements in most domains of health status compared with placebo. In particular, MH scores for PMDD and PDMA subgroups were higher (better) for sarilumab $200 \mathrm{mg}$ Q2W versus placebo [234].

Outside the phase III studies, tocilizumab use has been associated with decreased depressive manifestations (using the Hospital Anxiety and Depression Scale, which comprises two subscales [one measuring depression and the other anxiety] of seven items) in a small study of patients with RA [235].

\section{Effect of Sarilumab and Tocilizumab on Fatigue}

In MOBILITY, 24 weeks' treatment with sarilumab $200 \mathrm{mg}$ Q2W resulted in improvement from baseline by week 24 in Functional Assessment of Chronic Illness Therapy-Fatigue (FACIT-F) scores that were clinically meaningful and persisted until week 52 [236]. In TARGET, improvements in the FACIT-F scores with sarilumab $200 \mathrm{mg}$ Q2W were seen 2 weeks after the start of treatment, and greater improvements versus placebo at week 12 were maintained at week 24 [237]. Similar results have been seen with tocilizumab in the OPTION [45] and TOWARD studies [46].

\section{Effect of Sarilumab and Tocilizumab on Pain} Improvements in the pain VAS with sarilumab $200 \mathrm{mg}$ Q2W were approximately double those obtained with placebo in MOBILITY and TARGET by week 12 (- 30 vs. - 15) [39, 40]. Overall, with sarilumab $200 \mathrm{mg}$ Q2W in MOBILITY and TARGET, pain was improved by $\geq 30 \%$ in $50-60 \%$ of patients $[39,40]$. A recent post hoc analysis reported the proportions of patients achieving $\geq 30 \% / \geq 50 \% / \geq 70 \%$ pain VAS improvements and median time to first pain VAS $\geq 50 \%$ improvement in MOBILITY and TARGET [238]. Median time to first pain $\geq 50 \%$ improvement was 12 weeks in patients receiving sarilumab $200 \mathrm{mg}$ Q2W compared with 24 weeks in patients receiving placebo [238].

\section{Effect of Sarilumab and Tocilizumab on Morning Stiffness}

The effects of sarilumab on morning stiffness were measured using a VAS in TARGET, and showed an improvement in scores of -30 at week 12 (versus - 13 with placebo) and -34 at week 24 (versus - 22 with placebo) [237]. Morning stiffness was not measured in the tocilizumab phase III program, but in a German open-label study (TAMARA), major improvements in morning stiffness were observed in the first 4 weeks of treatment with IV tocilizumab $8 \mathrm{mg} / \mathrm{kg}$ Q4W, with further improvement until week 24 [239].

\section{Monotherapy with Sarilumab or Tocilizumab}

\section{Sarilumab Monotherapy}

The MONARCH study compared the effects of sarilumab $200 \mathrm{mg}$ Q2W and adalimumab $40 \mathrm{mg}$ Q2W on a variety of patient-reported outcomes [240]. After 24 weeks of treatment, and compared with adalimumab, sarilumab resulted in significantly greater improvements in HAQ-DI (decreases from 1.6 at baseline of -0.61 and -0.43 , respectively). By week $24,65 \%$ of patients had an improvement of HAQ-DI $\geq 0.22$ and $62 \%$ had an improvement $\geq 0.3$ (54\% and $48 \%$ with adalimumab, respectively). Sarilumab also resulted in larger improvements in Patient Global Assessment, pain VAS, and SF36 Physical Component Score (PCS), although, overall, between-group differences in FACIT-F and SF-36 Mental Component Score (MCS) were not significant. Improvements in four of eight SF-36 domains were significantly greater with sarilumab than with adalimumab (physical functioning, body pain, and role-physical, and social functioning). Greater changes were also reported for sarilumab versus adalimumab in RA impact of disease, a measure with seven 
weighted domains covering pain, functional disability, fatigue, emotional well-being, sleep, coping, and physical well-being [241]. A recent post hoc analysis of MONARCH reported that the median time to first pain $\geq 50 \%$ improvement in MONARCH was 12 weeks in patients receiving sarilumab $200 \mathrm{mg}$ Q2W, compared with 24 weeks in patients receiving placebo [238]. Morning stiffness was also evaluated using a VAS severity scale $(0 \mathrm{~mm}$ [no problem] to $100 \mathrm{~mm}$ [major problem]) [240]. At week 24, improvements in morning stiffness VAS were greater with sarilumab treatment than with adalimumab, and more patients $(73.9 \%$ vs. $62.2 \%)$ reported improvements greater than or equal to the morning stiffness minimal clinically important differences (MCID) of $\geq 10$ units.

\section{Tocilizumab Monotherapy}

The effects of IV tocilizumab monotherapy on patient-reported outcomes have been reported from AMBITION (compared with MTX) and ADACTA (compared with adalimumab) over 24 weeks [242]. In AMBITION, tocilizumabtreated patients reported significantly greater mean improvements in FACIT-F (8.7 vs. 5.7; SF36 PCS: 9.8 vs. 7.8) and five SF-36 domains (physical functioning, bodily pain, vitality, social functioning, and mental health) than with MTX [242].

The proportions of patients reporting improvements above the MCID depended on the outcome measured. In AMBITION, 24-44\% of tocilizumab-treated patients reported scores at least equal to normative values across HAQDI, FACIT-F, and SF-36 PCS/MCS, and 30-52\% across SF-36 domains at week 24 compared with $15-42 \%$ and $21-45 \%$ of MTX-treated patients, respectively [242].

In ADACTA, tocilizumab-treated patients reported significantly greater improvements in Patient Global Assessment (- 42.3 vs. -31.8$)$, pain (- 40.1 vs. -28.7$)$, SF-36 MCS (7.9 vs. 5.0), and three SF-36 domains than with adalimumab (role-physical, vitality, and social functioning) [242]. Overall, $58-83 \%$ of tocilizumab-treated patients reported improvements at least equal to the MCID. The proportion of tocilizumab-treated patients reporting scores at least equal to normative values ranged between $22-49 \%$ for HAQ-DI, FACIT-F, and SF-36 PCS/ MCS (14-38\% with adalimumab), and $23-41 \%$ across SF-36 domains at week 24 (17-33\% with adalimumab).

\section{SAFETY AND TOLERABILITY OF IL-6 BLOCKADE}

Overall safety profiles of sarilumab and tocilizumab are consistent with IL-6R blockade and the route of administration, and in ASCERTAIN, no clinically meaningful differences in adverse events were seen between SC sarilumab and IV tocilizumab over 24 weeks [204]. The most useful clinical perspectives on the safety of any pharmacologic intervention develop over time after the completion of the phase III studies, and more patients are treated for longer periods of time in clinical practice in addition to clinical studies. For sarilumab, Fleischmann et al. [163] have reported an integrated safety analysis of 9000-PY exposure to sarilumab: the overall incidence rates of serious adverse events were 9.4/100 and 6.7/100 PY, respectively, in the combination and monotherapy groups. For tocilizumab, similar integrated and long-term analyses have also been published [164, 243]. Mohan et al. [243] showed that the overall rate of serious adverse events in the integrated clinical trial population of $>22,000$ PY was $14.2 / 100 \mathrm{PY}$, and in a global postmarketing population included $>600,000$ patients; the overall spontaneous reporting rate of adverse events of special interest was 9.4 cases/100 patients.

In addition to the insights from these postmarketing studies, a number of real-world and registry-based studies provide additional insight into the safety profile of these agents in the wider population of patients with RA. While data from some registries have suggested an increased risk of infections, including serious infections, with agents that inhibit IL-6 signaling [244-247], a comparative head-to-head analysis of the safety of tocilizumab and TNF inhibitors in the Japanese REAL registry did not find a higher risk for serious adverse events or serious infections with tocilizumab compared 
with TNF inhibitors after adjustment for potentially confounding factors. The use of oral corticosteroids in patients receiving tocilizumab, however, was a significant risk factor for both serious adverse events and serious infections [248].

In a Japanese 26-week, real-world observational study among $>1000$ patients with RA, the safety profile of SC tocilizumab was consistent with that in clinical trials and for IV tocilizumab. Infections and infestations were the most commonly reported adverse events $(7.4 \%$ of patients) and accounted for the majority of serious adverse events $(1.7 \%$ of patients; 2 cases of pneumonia and 2 cases of bacterial pneumonia) [249].

The most frequent laboratory parameter changes reported in sarilumab/tocilizumab trials were decreased ANC and increases in liver transaminase levels (aspartate aminotransferase [AST] and alanine aminotransferase [ALT]) $[163,164]$, hence it is recommended that ANC counts, AST/ALT levels, and platelet counts are monitored after starting therapy and regularly thereafter. Lipid changes are also observed as described in the "RA and CVD" section above, although there is no increased risk of major $\mathrm{CV}$ events with IL-6R blockade versus anti-TNF $\alpha$ bDMARDs [162]. Therefore, lipid parameters should be assessed 4-8 weeks following initiation of treatment and regularly thereafter.

As highlighted in the "RA and Infections" section above, the risk of infections is an ongoing clinical consideration in all patients with RA, irrespective of treatment mechanism of action. Patients should therefore be closely monitored for the development of signs and manifestations of infection during treatment with IL-6R. This is particularly true in elderly patients, in whom more infections are seen in general, irrespective of disease or treatment [250]. IL-6R blockers should not be administered during an active infection, and if a serious infection develops, the IL-6R blockers should be temporarily discontinued until the infection is controlled [11-14].

Sarilumab studies have shown that neutropenia is not associated with a higher incidence of infections, including serious infections [163], and a margination hypothesis has been postulated [205]. In this model, "margination" is explained as the redistribution of the neutrophils from the vascular compartment into the vascular wall or other tissues (such as bone marrow), without change in their functionality. The marginated neutrophils remain available in case of an infection and can "demarginate" to mount a host response. Lok et al. [202] showed that tocilizumab did not affect neutrophil function, activation, or apoptosis ex vivo and, using radiolabeled neutrophils injected into human subjects, that tocilizumab affects neutrophil trafficking to the bone marrow.

Gastrointestinal (GI) perforation has been reported primarily as a complication of diverticulitis in patients with RA. An integrated safety analysis reported 26 cases of GI perforation (2.8/ $1000 \mathrm{PY}$ ) in patients who received tocilizumab compared with no cases in control csDMARD groups; 18 of these perforations occurred in the colon [164]. An analysis of the global postmarketing database for tocilizumab, which included data for 606,937 patients, identified 632 cases of GI perforation translating to a rate of 0.1 cases/ 100 patients [243]. An integrated analysis of sarilumab reported an incidence of GI perforation of $0.1 / 100$ PY with sarilumab in combination with csDMARDs, but no cases with sarilumab monotherapy with 812 PY follow-up [163].

Hypofibrinogenemia has been noted as a potential adverse effect during tocilizumab treatment in a small case series of seven patients [251]. This small group of patients (median age 60 years) received tocilizumab $8 \mathrm{mg} / \mathrm{kg}$ over a 1-year period and all exhibited low levels of plasma fibrinogen despite normal routine coagulation tests and no evidence of liver failure or disseminated intravascular coagulation (DIC). The authors suggest that, while low fibrinogen levels in the context of normal coagulation tests do not warrant discontinuation of treatment, liver function tests are warranted to rule out DIC or hemophagocytic lymphohistiocytosis.

All bDMARDs have the potential to induce an immunogenic response resulting in the formation of antidrug antibodies (ADAs). ADAs to mAbs may be neutralizing or non-neutralizing, or demonstrate a transient or persistent 
response; those that are neutralizing and persistent ADAs are more likely to be clinically relevant than transient and/or non-neutralizing ADAs [252]. ADA incidences cannot be compared across different bDMARDs, partly because of the different assays needed for different products; however, the development of ADAs has been reported with sarilumab [41] and tocilizumab [253] treatment. Any impact of an ADA can be compared with different agents and, importantly, unlike infliximab and adalimumab, with IL-6R inhibitors the presence of ADAs has not been associated with a lack or loss of efficacy relative to ADA-negative patients [254].

\section{CONCLUSIONS}

RA is a chronic, debilitating autoimmune disorder characterized by inflammation of the synovial joint tissues. RA pathogenesis is driven by a complex network of proinflammatory cells and cytokines, and among the actors involved in the network of RA, IL-6 seems to be the most pleiotropic cytokine with the greatest number of downstream influences. IL- 6 can bind to various cell types around the body, and increased production of IL- 6 can lead to heightened activation of cells within the joint, contributing to the RA disease state. However, beyond the joint, IL-6 is also known to contribute to various extra-articular manifestations and life-threatening comorbidities tightly linked to an existing RA condition.

IL-6R blockade treatments have been shown to cause clinically important improvements in RA clinical endpoints in patients with mild to severe active RA. The leading approved IL-6R inhibitors, sarilumab and tocilizumab, have produced statistically significant improvements in the signs and manifestations of RA when used as monotherapy or in combination with csDMARDs, as defined by the ACR, CRP and $\mathrm{ESR}, \mathrm{CDAI}$, and radiographic progression measures, cementing IL-6R blockade as a robust treatment option for RA. However, beyond the joint, the extra-articular manifestations linked to RA including anemia, morning stiffness, pain, weight and body composition, and comorbidities linked to RA that include osteoporosis, CVD and pulmonary disease, infections, depression, T2D, and malignancies have also previously been investigated as IL- 6 treatment targets. Clinical evidence in a range of clinical studies has indicated that use of IL-6R blockade with sarilumab or tocilizumab can improve these IL-6-linked conditions to varying extents, to ultimately improve patient disease states and quality of life. To this end, such findings indicate that sarilumab and tocilizumab can be supported as important treatments for certain extra-articular manifestations and comorbidities of RA, in addition to manifestations within the joint. The impacts of IL-6R blockade treatment effects can be observed when explored from both a clinician's perspective through clinical efficacy outcome measures, and also when viewed from a patient's perspective through the use of patient-reported outcome assessments, which measure variables including pain, physical functioning, and sleep disturbance.

\section{ACKNOWLEDGEMENTS}

Funding. This review was funded by Sanofi Genzyme (Cambridge, USA) and Regeneron Pharmaceuticals, Inc. (Tarrytown, USA). The Rapid Service Fee was funded by Sanofi Genzyme.

Medical Writing Assistance. Medical writing support (Matthew Howes, PhD, of Adelphi Communications Ltd, Macclesfield, UK) under the direction of the author was provided by Sanofi Genzyme (Cambridge, USA) and Regeneron Pharmaceuticals, Inc. (Tarrytown, USA) in accordance with Good Publication Practice (GPP3) guidelines.

Authorship. All named authors meet the International Committee of Medical Journal Editors (ICMJE) criteria for authorship for this article, take responsibility for the integrity of the work as a whole, and have given their approval for this version to be published. 
Disclosures. Ennio G. Favalli has received consulting fees and/or speaking engagements from AbbVie, Bristol-Myers Squibb, Lilly, Merck Sharp \& Dohme, Pfizer, Roche, Sanofi Genzyme, and Union Chimique Belge.

Compliance with Ethics Guidelines. This article is based on previously conducted studies and does not contain any studies with human participants or animals performed by any of the authors.

Data Availability. Data sharing is not applicable to this article as no datasets were generated or analyzed.

Open Access. This article is licensed under a Creative Commons Attribution-NonCommercial 4.0 International License, which permits any non-commercial use, sharing, adaptation, distribution and reproduction in any medium or format, as long as you give appropriate credit to the original author(s) and the source, provide a link to the Creative Commons licence, and indicate if changes were made. The images or other third party material in this article are included in the article's Creative Commons licence, unless indicated otherwise in a credit line to the material. If material is not included in the article's Creative Commons licence and your intended use is not permitted by statutory regulation or exceeds the permitted use, you will need to obtain permission directly from the copyright holder. To view a copy of this licence, visit http://creativecommons.org/licenses/by$\mathrm{nc} / 4.0 /$.

\section{REFERENCES}

1. Cross M, Smith E, Hoy D, et al. The global burden of rheumatoid arthritis: estimates from the global burden of disease 2010 study. Ann Rheum Dis. 2014;73:1316-22. annrheumdis-2013-204627.

2. Selmi C, Kon E, De Santis M, et al. How advances in personalized medicine will change rheumatology. Per Med. 2018;15:75-8. https://doi.org/10.2217/ pme-2017-0079.
3. Cantini F, Niccoli L, Nannini C, et al. Tailored firstline biologic therapy in patients with rheumatoid arthritis, spondyloarthritis, and psoriatic arthritis. Semin Arthritis Rheum. 2016;45:519-32. https:// doi.org/10.1016/j.semarthrit.2015.10.001.

4. Cantini F, Niccoli L, Nannini C, et al. Second-line biologic therapy optimization in rheumatoid arthritis, psoriatic arthritis, and ankylosing spondylitis. Semin Arthritis Rheum. 2017;47: 183-92. https://doi.org/10.1016/j.semarthrit.2017. 03.008 .

5. Favalli EG, Raimondo MG, Becciolini A, et al. The management of first-line biologic therapy failures in rheumatoid arthritis: Current practice and future perspectives. Autoimmun Rev. 2017;16:1185-95. https://doi.org/10.1016/j.autrev.2017.10.002.

6. Todoerti M, Favalli EG, Iannone F, et al. Switch or swap strategy in rheumatoid arthritis patients failing TNF inhibitors? Results of a modified Italian Expert Consensus. Rheumatology (Oxford). 2018;57(Suppl 7):vii42-vii53. https://doi.org/10. 1093/rheumatology/key195.

7. Nishimoto N, Terao K, Mima T, et al. Mechanisms and pathologic significances in increase in serum interleukin-6 (IL-6) and soluble IL-6 receptor after administration of an anti-IL-6 receptor antibody, tocilizumab, in patients with rheumatoid arthritis and Castleman disease. Blood. 2008;112:3959-64. https://doi.org/10.1182/blood-2008-05-155846.

8. Narazaki M, Tanaka T, Kishimoto T. The role and therapeutic targeting of IL-6 in rheumatoid arthritis. Expert Rev Clin Immunol. 2017;13:535-51. https://doi.org/10.1080/1744666x.2017.1295850.

9. Raimondo MG, Biggioggero M, Crotti C, et al. Profile of sarilumab and its potential in the treatment of rheumatoid arthritis. Drug Des Devel Ther. 2017;11:1593-603. https://doi.org/10.2147/dddt. s100302.

10. Biggioggero M, Crotti C, Becciolini A, et al. Tocilizumab in the treatment of rheumatoid arthritis: an evidence-based review and patient selection. Drug Des Devel Ther. 2019;13:57-70. https://doi.org/10. 2147/dddt.S150580.

11. Committee for Medicinal Products for Human Use. RoActemra Summary of Product Characteristics, https://www.medicines.org.uk/emc/product/6673/ smpc. 2019; Accessed 10 October 2019.

12. ACTEMRA (Tocilizumab). US prescribing information, https://www.gene.com/download/pdf/ actemra_prescribing.pdf. 2019; Accessed May 14 2020. 
13. Regeneron Sanofi Genzyme. Kevzara ${ }^{\circledR}$ (sarilumab) Prescribing Information, https://products.sanofi.us/ kevzara/kevzara.pdf. 2018; Accessed 10 October 2019.

14. Kevzara. Summary of Product Characteristics, https://www.medicines.org.uk/emc/medicine/ 33836. 2019; Accessed 12 August 2019.

15. Hirano T, Yasukawa K, Harada $\mathrm{H}$, et al. Complementary DNA for a novel human interleukin (BSF-2) that induces $\mathrm{B}$ lymphocytes to produce immunoglobulin. Nature. 1986;324:73-6. https:// doi.org/10.1038/324073a0.

16. Kishimoto T. The biology of interleukin-6. Blood. 1989;74:1-10.

17. Yamasaki K, Taga T, Hirata $\mathrm{Y}$, et al. Cloning and expression of the human interleukin-6 (BSF-2/IFN beta 2) receptor. Science. 1988;241:825-8. https:// doi.org/10.1126/science.3136546.

18. Paonessa G, Graziani R, De Serio A, et al. Two distinct and independent sites on IL-6 trigger gp 130 dimer formation and signalling. EMBO J. 1995;14: 1942-51.

19. Rose-John S. IL-6 trans-signaling via the soluble IL-6 receptor: importance for the pro-inflammatory activities of IL-6. Int J Biol Sci. 2012;8:1237-47. https://doi.org/10.7150/ijbs.4989.

20. Scheller J, Garbers C, Rose-John S. Interleukin-6: from basic biology to selective blockade of pro-inflammatory activities. Semin Immunol. 2014;26: 2-12. https://doi.org/10.1016/j.smim.2013.11.002.

21. Naugler WE, Karin M. The wolf in sheep's clothing: the role of interleukin- 6 in immunity, inflammation and cancer. Trends Mol Med. 2008;14:109-19. https://doi.org/10.1016/j.molmed.2007.12.007.

22. Heinrich PC, Behrmann I, Haan S, et al. Principles of interleukin (IL)-6-type cytokine signalling and its regulation. Biochem J. 2003;374:1-20. https://doi. org/10.1042/BJ20030407.

23. Hassan W, Ding L, Gao RY, et al. Interleukin-6 signal transduction and its role in hepatic lipid metabolic disorders. Cytokine. 2014;66:133-42. https:// doi.org/10.1016/j.cyto.2013.12.017.

24. Taub R. Liver regeneration: from myth to mechanism. Nat Rev Mol Cell Biol. 2004;5:836-47. https:// doi.org/10.1038/nrm1489.

25. Jostock T, Mullberg J, Ozbek S, et al. Soluble gp130 is the natural inhibitor of soluble interleukin-6 receptor transsignaling responses. Eur J Biochem. 2001;268:160-7. https://doi.org/10.1046/j.14321327.2001.01867.x.
26. Klareskog L, Wedren S, Alfredsson L. On the origins of complex immune-mediated disease: the example of rheumatoid arthritis. J Mol Med (Berl). 2009;87: 357-62. https://doi.org/10.1007/s00109-008-04379.

27. Firestein GS. The disease formerly known as rheumatoid arthritis. Arthritis Res Ther. 2014;16: 114. https://doi.org/10.1186/ar4593.

28. Darrah E, Andrade F. Rheumatoid arthritis and citrullination. Curr Opin Rheumatol. 2018;30:72-8. https://doi.org/10.1097/bor.0000000000000452.

29. McInnes IB, Schett G. The pathogenesis of rheumatoid arthritis. N Engl J Med. 2011;365: 2205-19. https://doi.org/10.1056/NEJMra1004965.

30. Benham H, Nel HJ, Law SC, et al. Citrullinated peptide dendritic cell immunotherapy in HLA risk genotype-positive rheumatoid arthritis patients. Sci Transl Med 2015;7:290ra287. DOI: 10.1126/scitranslmed.aaa9301.

31. Scherer HU, Huizinga TWJ, Kronke G, et al. The B cell response to citrullinated antigens in the development of rheumatoid arthritis. Nat Rev Rheumatol. 2018;14:157-69. https://doi.org/10.1038/ nrrheum.2018.10.

32. Yoshitake F, Itoh S, Narita H, et al. Interleukin-6 directly inhibits osteoclast differentiation by suppressing receptor activator of NF-kappaB signaling pathways. J Biol Chem. 2008;283:11535-40. https:// doi.org/10.1074/jbc.M607999200.

33. Gough A, Sambrook P, Devlin J, et al. Osteoclastic activation is the principal mechanism leading to secondary osteoporosis in rheumatoid arthritis. J Rheumatol. 1998;25:1282-9.

34. De Benedetti F, Rucci N, Del Fattore A, et al. Impaired skeletal development in interleukin-6transgenic mice: a model for the impact of chronic inflammation on the growing skeletal system. Arthritis Rheum. 2006;54:3551-633. https:/doi. org/10.1002/art.22175.

35. Kwan Tat S, Padrines M, Theoleyre S, et al. IL-6, RANKL, TNF-alpha/IL-1: interrelations in bone resorption pathophysiology. Cytokine Growth Factor Rev. 2004;15:49-60.

36. Devlin RD, Reddy SV, Savino R, et al. IL-6 mediates the effects of IL-1 or TNF, but not PTHrP or $1,25(\mathrm{OH}) 2 \mathrm{D} 3$, on osteoclast-like cell formation in normal human bone marrow cultures. J Bone Miner Res. 1998;13:393-9. https://doi.org/10.1359/jbmr. 1998.13.3.393.

37. McInnes IB, Buckley CD, Isaacs JD. Cytokines in rheumatoid arthritis - shaping the immunological 
landscape. Nat Rev Rheumatol. 2016;12:63-8. https://doi.org/10.1038/nrrheum.2015.171.

38. Castell JV, Gomez-Lechon MJ, David M, et al. Interleukin- 6 is the major regulator of acute phase protein synthesis in adult human hepatocytes. FEBS Lett. 1989;242:237-9. https://doi.org/10.1016/ 0014-5793(89)80476-4.

39. Genovese MC, Fleischmann R, Kivitz AJ, et al. Sarilumab plus methotrexate in patients with active rheumatoid arthritis and inadequate response to methotrexate: Results of a phase III study. Arthritis Rheumatol. 2015;67:1424-37. https://doi.org/10. 1002/art.39093.

40. Fleischmann R, van Adelsberg J, Lin Y, et al. Sarilumab and nonbiologic disease-modifying antirheumatic drugs in patients with active rheumatoid arthritis and inadequate response or intolerance to tumor necrosis factor inhibitors. Arthritis Rheumatol. 2017;69:277-90. https://doi.org/10.1002/art. 39944.

41. Burmester GR, Lin Y, Patel R, et al. Efficacy and safety of sarilumab monotherapy versus adalimumab monotherapy for the treatment of patients with active rheumatoid arthritis (MONARCH): a randomised, double-blind, parallel-group phase III trial. Ann Rheum Dis. 2017;76:840-7. https://doi. org/10.1136/annrheumdis-2016-210310.

42. Burmester GR, Rubbert-Roth A, Cantagrel A, et al. A randomised, double-blind, parallel-group study of the safety and efficacy of subcutaneous tocilizumab versus intravenous tocilizumab in combination with traditional disease-modifying antirheumatic drugs in patients with moderate to severe rheumatoid arthritis (SUMMACTA study). Ann Rheum Dis. 2014;73:69-74. annrheumdis-2013-203523.

43. Kivitz A, Olech E, Borofsky M, et al. Subcutaneous tocilizumab versus placebo in combination with disease-modifying antirheumatic drugs in patients with rheumatoid arthritis. Arthritis Care Res (Hoboken). 2014;66:1653-61. https://doi.org/10. 1002/acr.22384.

44. Kremer JM, Blanco R, Brzosko M, et al. Tocilizumab inhibits structural joint damage in rheumatoid arthritis patients with inadequate responses to methotrexate: results from the double-blind treatment phase of a randomized placebo-controlled trial of tocilizumab safety and prevention of structural joint damage at one year. Arthritis Rheum. 2011;63:609-21. https://doi.org/10.1002/art.30158.

45. Smolen JS, Beaulieu A, Rubbert-Roth A, et al. Effect of interleukin-6 receptor inhibition with tocilizumab in patients with rheumatoid arthritis (OPTION study): a double-blind, placebo-controlled, randomised trial. Lancet. 2008;371:987-97. https:// doi.org/10.1016/s0140-6736(08)60453-5.

46. Genovese MC, McKay JD, Nasonov EL, et al. Interleukin-6 receptor inhibition with tocilizumab reduces disease activity in rheumatoid arthritis with inadequate response to disease-modifying antirheumatic drugs: the tocilizumab in combination with traditional disease-modifying antirheumatic drug therapy study. Arthritis Rheum. 2008;58: 2968-80. https://doi.org/10.1002/art.23940.

47. Emery P, Keystone E, Tony HP, et al. IL-6 receptor inhibition with tocilizumab improves treatment outcomes in patients with rheumatoid arthritis refractory to anti-tumour necrosis factor biologicals: results from a 24-week multicentre randomised placebo-controlled trial. Ann Rheum Dis. 2008;67: 1516-23. https://doi.org/10.1136/ard.2008.092932.

48. Bijlsma JWJ, Welsing PMJ, Woodworth TG, et al. Early rheumatoid arthritis treated with tocilizumab, methotrexate, or their combination (U-Act-Early): a multicentre, randomised, double-blind, doubledummy, strategy trial. Lancet. 2016;388:343-55. https://doi.org/10.1016/s0140-6736(16)30363-4.

49. Burmester GR, Rigby WF, van Vollenhoven RF, et al. Tocilizumab combination therapy or monotherapy or methotrexate monotherapy in methotrexatenaive patients with early rheumatoid arthritis: 2-year clinical and radiographic results from the randomised, placebo-controlled FUNCTION trial. Ann Rheum Dis. 2017;76:1279-84. https://doi.org/ 10.1136/annrheumdis-2016-210561.

50. Dougados M, Kissel K, Sheeran T, et al. Adding tocilizumab or switching to tocilizumab monotherapy in methotrexate inadequate responders: 24-week symptomatic and structural results of a 2-year randomised controlled strategy trial in rheumatoid arthritis (ACT-RAY). Ann Rheum Dis. 2013;72:43-50. https://doi.org/10.1136/ annrheumdis-2011-201282.

51. Gabay C, Emery P, van Vollenhoven R, et al. Tocilizumab monotherapy versus adalimumab monotherapy for treatment of rheumatoid arthritis (ADACTA): a randomised, double-blind, controlled phase 4 trial. Lancet. 2013;381:1541-50. https:// doi.org/10.1016/s0140-6736(13)60250-0.

52. Felson DT, Anderson JJ, Lange ML, et al. Should improvement in rheumatoid arthritis clinical trials be defined as fifty percent or seventy percent improvement in core set measures, rather than twenty percent? Arthritis Rheum. 1998;41:1564-70.

53. Burmester GR, Rubbert-Roth A, Cantagrel A, et al. Efficacy and safety of subcutaneous tocilizumab versus intravenous tocilizumab in combination with traditional DMARDs in patients with RA at 
week 97 (SUMMACTA). Ann Rheum Dis. 2016;75: 68-74. https://doi.org/10.1136/annrheumdis-2015207281.

54. Burmester GR, Rigby WF, van Vollenhoven RF, et al. Tocilizumab in early progressive rheumatoid arthritis: FUNCTION, a randomised controlled trial. Ann Rheum Dis. 2016;75:1081-91. https://doi.org/ 10.1136/annrheumdis-2015-207628.

55. Abdallah H, Hsu JC, Lu P, et al. Pharmacokinetic and pharmacodynamic analysis of subcutaneous tocilizumab in patients with rheumatoid arthritis from 2 randomized, controlled trials: SUMMACTA and BREVACTA. J Clin Pharmacol. 2017;57:459-68. https://doi.org/10.1002/jcph.826.

56. Genovese MC, van Adelsberg J, Fan C, et al. Two years of sarilumab in patients with rheumatoid arthritis and an inadequate response to MTX: safety, efficacy and radiographic outcomes. Rheumatology (Oxford). 2018;57:1423-31. https:// doi.org/10.1093/rheumatology/key121.

57. Genovese MC, van der Heijde D, Lin Y, et al. Longterm safety and efficacy of sarilumab plus methotrexate on disease activity, physical function and radiographic progression: 5 years of sarilumab plus methotrexate treatment. RMD Open. 2019;5: e000887. https://doi.org/10.1136/rmdopen-2018000887.

58. Boyapati A, Msihid J, Schwartzman S, et al. 069 High baseline serum IL-6 identifies a subgroup of rheumatoid arthritis patients with rapid joint damage and clinical progression and predicts increased sarilumab treatment response. Rheumatology 58: [Abstract number: L08]. Epub ahead of print Apr 3. DOI: 10.1093/rheumatology/kez106. 068.

59. Fleischmann RM, Halland AM, Brzosko M, et al. Tocilizumab inhibits structural joint damage and improves physical function in patients with rheumatoid arthritis and inadequate responses to methotrexate: LITHE study 2-year results. J Rheumatol. 2013;40:113-26. https://doi.org/10. 3899/jrheum.120447.

60. Smolen JS, Breedveld FC, Burmester GR, et al. Treating rheumatoid arthritis to target: 2014 update of the recommendations of an international task force. Ann Rheum Dis. 2016;75:3-15. https://doi. org/10.1136/annrheumdis-2015-207524.

61. Favalli EG, Biggioggero M, Meroni PL. Methotrexate for the treatment of rheumatoid arthritis in the biologic era: still an "anchor" drug? Autoimmun Rev. 2014;13:1102-8. https://doi.org/10.1016/j. autrev.2014.08.026.
62. Becciolini A, Biggioggero M, Favalli EG. The role of methotrexate as combination therapy with etanercept in rheumatoid arthritis: Retrospective analysis of a local registry. J Int Med Res. 2016;44:113-18. https://doi.org/10.1177/0300060515593261.

63. Favalli EG, Becciolini A, Biggioggero $M$, et al. The role of concomitant methotrexate dosage and maintenance over time in the therapy of rheumatoid arthritis patients treated with adalimumab or etanercept: retrospective analysis of a local registry. Drug Des Devel Ther. 2018;12:1421-9. https://doi. org/10.2147/dddt.S162286.

64. EXCELLA GmbH. Methotrexate US Prescribing Information, https://www.accessdata.fda.gov/ drugsatfda_docs/label/2016/008085s066lbl.pdf. 2016; Accessed 10 October 2019.

65. Lie E, van der Heijde D, Uhlig T, et al. Effectiveness and retention rates of methotrexate in psoriatic arthritis in comparison with methotrexate-treated patients with rheumatoid arthritis. Ann Rheum Dis. 2010;69:671-6. https://doi.org/10.1136/ard.2009. 113308 .

66. Nikiphorou E, Negoescu A, Fitzpatrick JD, et al. Indispensable or intolerable? Methotrexate in patients with rheumatoid and psoriatic arthritis: a retrospective review of discontinuation rates from a large UK cohort. Clin Rheumatol. 2014;33:609-14. https://doi.org/10.1007/s10067-014-2546-X.

67. Burmester GR, Amital H, Rubbert-Roth A, et al. SAT0137 Patients (pts) switched to sarilumab from adalimumab achieve clinically important improvements in ra disease activity: results from monarch trial open-label extension (OLE). Ann Rheum Dis. 2019;78:1138-9. https://doi.org/10.1136/ annrheumdis-2019-eular.4646.

68. Jones G, Sebba A, Gu J, et al. Comparison of tocilizumab monotherapy versus methotrexate monotherapy in patients with moderate to severe rheumatoid arthritis: the AMBITION study. Ann Rheum Dis. 2010;69:88-96. https://doi.org/10. 1136/ard.2008.105197.

69. Wilson A, Yu HT, Goodnough LT, et al. Prevalence and outcomes of anemia in rheumatoid arthritis: a systematic review of the literature. Am J Med. 2004;116(Suppl 7A):50S-57S. https://doi.org/10. 1016/j.amjmed.2003.12.012.

70. Song SN, Iwahashi M, Tomosugi N, et al. Comparative evaluation of the effects of treatment with tocilizumab and TNF-alpha inhibitors on serum hepcidin, anemia response and disease activity in rheumatoid arthritis patients. Arthritis Res Ther. 2013;15:R141. https://doi.org/10.1186/ar4323. 
71. Raj DS. Role of interleukin-6 in the anemia of chronic disease. Semin Arthritis Rheum. 2009;38: 382-8. https://doi.org/10.1016/j.semarthrit.2008. 01.006 .

72. Weiss G, Schett G. Anaemia in inflammatory rheumatic diseases. Nat Rev Rheumatol. 2013;9:205-15. https://doi.org/10.1038/nrrheum.2012.183.

73. Rivera S, Liu L, Nemeth E, et al. Hepcidin excess induces the sequestration of iron and exacerbates tumor-associated anemia. Blood. 2005;105: 1797-802. https://doi.org/10.1182/blood-2004-083375 .

74. Lee P, Peng H, Gelbart T, et al. The IL-6- and lipopolysaccharide-induced transcription of hepcidin in HFE-, transferrin receptor 2-, and beta 2-microglobulin-deficient hepatocytes. Proc Natl Acad Sci USA. 2004;101:9263-5. https://doi.org/10. 1073/pnas.0403108101.

75. Nemeth E, Tuttle MS, Powelson J, et al. Hepcidin regulates cellular iron efflux by binding to ferroportin and inducing its internalization. Science. 2004;306:2090-3. https://doi.org/10.1126/science. 1104742 .

76. Burmester GR, Hagino O, Dong $Q$, et al. Unique Changes in Hemoglobin with Sarilumab Versus Adalimumab Are Independent of Better Disease Control in Patients with Rheumatoid Arthritis (RA). In: ACR/ARHP Annual Meeting, Chicago, IL, Oct 22 2018, Arthritis Rheumatol.

77. Dougados M, Choy E, Kameda H, et al. IL-6R blockade with sarilumab plus methotrexate results in changes in clinical and laboratory parameters associated with chronic inflammation in patients with moderate-to-severe RA in a phase 3 study. Arthritis Rheumatol. 2015;67:3336-8.

78. Isaacs JD, Harari O, Kobold U, et al. Effect of tocilizumab on haematological markers implicates interleukin- 6 signalling in the anaemia of rheumatoid arthritis. Arthritis Res Ther. 2013;15:R204. https://doi.org/10.1186/ar4397.

79. Pollard LC, Choy EH, Gonzalez J, et al. Fatigue in rheumatoid arthritis reflects pain, not disease activity. Rheumatology (Oxford). 2006;45:885-9. https://doi.org/10.1093/rheumatology/kel021.

80. Overman CL, Kool MB, Da Silva JA, et al. The prevalence of severe fatigue in rheumatic diseases: an international study. Clin Rheumatol. 2016;35: 409-15. https://doi.org/10.1007/s10067-015-30356.

81. Hewlett S, Cockshott Z, Byron M, et al. Patients' perceptions of fatigue in rheumatoid arthritis: overwhelming, uncontrollable, ignored. Arthritis
Rheum. 2005;53:697-702. https://doi.org/10.1002/ art.21450.

82. Tugwell P, Boers M, Brooks P, et al. OMERACT: an international initiative to improve outcome measurement in rheumatology. Trials. 2007;8:38. https://doi.org/10.1186/1745-6215-8-38.

83. Mastorakos G, Weber JS, Magiakou MA, et al. Hypothalamic-pituitary-adrenal axis activation and stimulation of systemic vasopressin secretion by recombinant interleukin-6 in humans: potential implications for the syndrome of inappropriate vasopressin secretion. J Clin Endocrinol Metab. 1994;79:934-9. https://doi.org/10.1210/jcem.79.4. 7962300 .

84. Eijsbouts AM, van den Hoogen FH, Laan RF, et al. Hypothalamic-pituitary-adrenal axis activity in patients with rheumatoid arthritis. Clin Exp Rheumatol. 2005;23:658-64.

85. Papadopoulos AS, Cleare AJ. Hypothalamic-pituitary-adrenal axis dysfunction in chronic fatigue syndrome. Nat Rev Endocrinol. 2011;8:22-32. https://doi.org/10.1038/nrendo.2011.153.

86. Bykerk VP, Lie E, Bartlett SJ, et al. Establishing a core domain set to measure rheumatoid arthritis flares: report of the OMERACT 11 RA flare Workshop. J Rheumatol. 2014;41:799-809. https://doi.org/10. 3899/jrheum.131252.

87. Cutolo M. Circadian rhythms and rheumatoid arthritis. Joint Bone Spine. 2019;86:327-33. https:// doi.org/10.1016/j.jbspin.2018.09.003.

88. Arvidson NG, Gudbjornsson B, Elfman L, et al. Circadian rhythm of serum interleukin-6 in rheumatoid arthritis. Ann Rheum Dis. 1994;53: 521-4. https://doi.org/10.1136/ard.53.8.521.

89. Madhok R, Crilly A, Watson J, et al. Serum interleukin 6 levels in rheumatoid arthritis: correlations with clinical and laboratory indices of disease activity. Ann Rheum Dis. 1993;52:232-4. https:// doi.org/10.1136/ard.52.3.232.

90. Heiberg T, Finset A, Uhlig T, et al. Seven year changes in health status and priorities for improvement of health in patients with rheumatoid arthritis. Ann Rheum Dis. 2005;64:191-5. https:// doi.org/10.1136/ard.2004.022699.

91. Taylor P, Manger B, Alvaro-Gracia J, et al. Patient perceptions concerning pain management in the treatment of rheumatoid arthritis. J Int Med Res. 2010;38:1213-24. https://doi.org/10.1177/14732300 1003800402. 
92. Phillips K, Clauw DJ. Central pain mechanisms in the rheumatic diseases: future directions. Arthritis Rheum. 2013;65:291-302.

93. Courvoisier DS, Agoritsas T, Glauser J, et al. Pain as an important predictor of psychosocial health in patients with rheumatoid arthritis. Arthritis Care Res (Hoboken). 2012;64:190-6. https://doi.org/10. 1002/acr.20652.

94. Nicassio PM, Ormseth SR, Kay M, et al. The contribution of pain and depression to self-reported sleep disturbance in patients with rheumatoid arthritis. Pain. 2012;153:107-12. https://doi.org/10.1016/j. pain.2011.09.024.

95. von Banchet GS, Kiehl M, Schaible HG. Acute and long-term effects of IL- 6 on cultured dorsal root ganglion neurones from adult rat. J Neurochem. 2005;94:238-48. https://doi.org/10.1111/j.14714159.2005.03185.x.

96. Vazquez E, Kahlenbach J, Segond von Banchet G, et al. Spinal interleukin-6 is an amplifier of arthritic pain in the rat. Arthritis Rheum 2012;64:2233-42. DOI: $10.1002 /$ art.34384.

97. Brenn D, Richter F, Schaible HG. Sensitization of unmyelinated sensory fibers of the joint nerve to mechanical stimuli by interleukin- 6 in the rat: an inflammatory mechanism of joint pain. Arthritis Rheum. 2007;56:351-9. https://doi.org/10.1002/art. 22282.

98. Boettger MK, Weber K, Gajda M, et al. Spinally applied ketamine or morphine attenuate peripheral inflammation and hyperalgesia in acute and chronic phases of experimental arthritis. Brain Behav Immun. 2010;24:474-85. https://doi.org/10. 1016/j.bbi.2009.12.002.

99. Santo RCE, Fernandes KZ, Lora PS, et al. Prevalence of rheumatoid cachexia in rheumatoid arthritis: a systematic review and meta-analysis. J Cachexia Sarcopenia Muscle. 2018;9:816-25. https://doi.org/ 10.1002/jcsm.12320.

100. Carvalho GD, Bonfiglioli K, Caparbo VF, et al. Changes to body composition in women with longstanding established rheumatoid arthritis: differences by level of disease activity. J Clin Densitom. 2019;S1094-6950(19)30070-8. https://doi.org/10. 1016/j.jocd.2019.06.002.

101. Lutz TA. The brain needs interleukin-6 (IL-6) to maintain a "healthy" energy balance. Focus on "IL-6 ameliorates defective leptin sensitivity in DIO ventromedial hypothalamic nucleus neurons". Am J Physiol Regul Integr Comp Physiol. 2016;311: R989-R991. DOI: 10.1152/ajpregu.00426.2016.
102. Masuko K. Rheumatoid cachexia revisited: a metabolic co-morbidity in rheumatoid arthritis. Front Nutr. 2014;1:20.

103. Swiergiel AH, Dunn AJ. The roles of IL-1, IL-6, and TNFalpha in the feeding responses to endotoxin and influenza virus infection in mice. Brain Behav Immun. 1999;13:252-65. https://doi.org/10.1006/ brbi.1999.0565.

104. McCarthy DO. Cytokines and the anorexia of infection: potential mechanisms and treatments. Biol Res Nurs. 2000;1:287-98. https://doi.org/10. $1177 / 109980040000100405$.

105. Wallenius $\mathrm{V}$, Wallenius $\mathrm{K}$, Ahren $\mathrm{B}$, et al. Interleukin-6-deficient mice develop mature-onset obesity. Nat Med. 2002;8:75-9. https://doi.org/10. 1038/nm0102-75.

106. Mishra D, Richard JE, Maric I, et al. Parabrachial interleukin- 6 reduces body weight and food intake and increases thermogenesis to regulate energy metabolism. Cell Rep. 2019;26(3011-3026):e3015. https://doi.org/10.1016/j.celrep.2019.02.044.

107. Younis S, Rosner I, Rimar D, et al. Interleukin 6 blockade-associated weight gain with abdominal enlargement in a patient with rheumatoid arthritis. J Clin Rheumatol. 2013;19:48-9. https://doi.org/10. 1097/RHU.0b013e31827cdda7.

108. Tournadre A, Pereira B, Dutheil F, et al. Changes in body composition and metabolic profile during interleukin 6 inhibition in rheumatoid arthritis. J Cachexia Sarcopenia Muscle. 2017;8:639-46. https://doi.org/10.1002/jcsm.12189.

109. Gremese E, Carletto A, Padovan M, et al. Obesity and reduction of the response rate to anti-tumor necrosis factor alpha in rheumatoid arthritis: an approach to a personalized medicine. Arthritis Care Res (Hoboken). 2013;65:94-100. https://doi.org/10. 1002/acr.21768.

110. Dougados M. Comorbidities in rheumatoid arthritis. Curr Opin Rheumatol. 2016;28:282-8. https:// doi.org/10.1097/bor.0000000000000267.

111. Gullick NJ, Scott DL. Co-morbidities in established rheumatoid arthritis. Best Pract Res Clin Rheumatol. 2011;25:469-83. https://doi.org/10.1016/j.berh. 2011.10.009.

112. Ferreira RC, Freitag DF, Cutler AJ, et al. Functional IL6R 358Ala allele impairs classical il-6 receptor signaling and influences risk of diverse inflammatory diseases. PLoS Gene. 2013;9:e1003444. https:// doi.org/10.1371/journal.pgen.1003444.

113. Selmi C, Shoenfeld Y. Open questions in autoimmunity: discussions from the 2013 controversies in 
rheumatology and autoimmunity meeting. BMC Med. 2014;12:50. https://doi.org/10.1186/17417015-12-50.

114. Biggioggero M, Mesina F, Favalli EG. The Use of Rheumatic Disease Comorbidity Index for Predicting Clinical Response and Retention Rate in a Cohort of Rheumatoid Arthritis Patients Receiving Tumor Necrosis Factor Alpha Inhibitors. Biomed Res Int 2019: 6107217. Epub ahead of print Jan 10. DOI: $10.1155 / 2019 / 6107217$.

115. Luque Ramos A, Redeker I, Hoffmann F, et al. Comorbidities in patients with rheumatoid arthritis and their association with patient-reported outcomes: Results of claims data linked to questionnaire survey. J Rheumatol. 2019;46:564-71. https:// doi.org/10.3899/jrheum.180668.

116. Cavalli G, Favalli EG. Cardiovascular disease in patients with rheumatoid arthritis: impact of classic and disease-specific risk factors. Ann Transl Med. 2018;6:S82. https://doi.org/10.21037/atm.2018.10. 72.

117. Bongartz T, Nannini C, Medina-Velasquez YF, et al. Incidence and mortality of interstitial lung disease in rheumatoid arthritis: a population-based study. Arthritis Rheum. 2010;62:1583-91. https://doi.org/ 10.1002/art.27405.

118. Doran MF, Crowson CS, Pond GR, et al. Frequency of infection in patients with rheumatoid arthritis compared with controls: a population-based study. Arthritis Rheum. 2002;46:2287-93. https://doi.org/ $10.1002 /$ art.10524.

119. Smitten AL, Choi HK, Hochberg MC, et al. The risk of herpes zoster in patients with rheumatoid arthritis in the United States and the United Kingdom. Arthritis Rheum. 2007;57:1431-8. https://doi. org/10.1002/art.23112.

120. Matcham F, Rayner L, Steer S, et al. The prevalence of depression in rheumatoid arthritis: a systematic review and meta-analysis. Rheumatology (Oxford). 2013;52:2136-48. https://doi.org/10.1093/ rheumatology/ket169.

121. Albrecht K, Luque Ramos A, Hoffmann F, et al. High prevalence of diabetes in patients with rheumatoid arthritis: results from a questionnaire survey linked to claims data. Rheumatology (Oxford). 2018;57: 329-36. https://doi.org/10.1093/rheumatology/ kex414.

122. Baecklund E, Iliadou A, Askling J, et al. Association of chronic inflammation, not its treatment, with increased lymphoma risk in rheumatoid arthritis. Arthritis Rheum. 2006;54:692-701. https://doi.org/ 10.1002/art.21675.
123. Forsblad D'Elia H, Larsen A, Waltbrand E, et al. Radiographic joint destruction in postmenopausal rheumatoid arthritis is strongly associated with generalised osteoporosis. Ann Rheum Dis. 2003;62: 617-23. https://doi.org/10.1136/ard.62.7.617.

124. Sinigaglia L, Varenna M, Girasole G, et al. Epidemiology of osteoporosis in rheumatic diseases. Rheum Dis Clin North Am. 2006;32:631-58. https://doi.org/10.1016/j.rdc.2006.07.002.

125. Canalis E, Delany AM. Mechanisms of glucocorticoid action in bone. Ann N Y Acad Sci. 2002;966: 73-81. https://doi.org/10.1111/j.1749-6632.2002. tb04204.x.

126. Kroger H, Honkanen R, Saarikoski S, et al. Decreased axial bone mineral density in perimenopausal women with rheumatoid arthritis-a population based study. Ann Rheum Dis. 1994;53:18-23. https://doi.org/10.1136/ard.53.1.18.

127. Lane NE, Pressman AR, Star VL, et al. Rheumatoid arthritis and bone mineral density in elderly women. The Study of Osteoporotic Fractures Research Group. J Bone Miner Res 1995;10:257-63. DOI: $10.1002 / \mathrm{jbmr} .5650100212$.

128. van Staa TP, Geusens P, Bijlsma JW, et al. Clinical assessment of the long-term risk of fracture in patients with rheumatoid arthritis. Arthritis Rheum. 2006;54:3104-12. https://doi.org/10.1002/art. 22117.

129. Abrahamsen B, Rohold A, Henriksen JE, et al. Correlations between insulin sensitivity and bone mineral density in non-diabetic men. Diabet Med. 2000;17:124-9. https://doi.org/10.1046/j.14645491.2000.00234.x.

130. Nakashima T, Penninger JM. RANKL and RANK as novel therapeutic targets for arthritis. Curr Opin Rheumatol. 2003;15:280-7.

131. Bustamante $M$, Nogues $\mathrm{X}$, Mellibovsky L, et al. Polymorphisms in the interleukin- 6 receptor gene are associated with bone mineral density and body mass index in Spanish postmenopausal women. Eur J Endocrinol. 2007;157:677-84. https://doi.org/10. 1530/eje-07-0389.

132. Gabay C, Msihid J, Paccard C, et al. Sarilumab Significantly Suppresses Circulating Biomarkers of Bone Resorption and Cardiovascular Risk Compared With Adalimumab: Biomarker Analysis From the Phase 3 MONARCH Study. In: Ann Rheum Dis 2017.

133. Boyapati A, Msihid J, Fiore S, et al. Sarilumab plus methotrexate suppresses circulating biomarkers of bone resorption and synovial damage in patients with rheumatoid arthritis and inadequate response to methotrexate: a biomarker study of MOBILITY. 
Arthritis Res Ther. 2016;18:225. https://doi.org/10. 1186/s13075-016-1132-9.

134. Gabay C, Msihid J, Zilberstein M, et al. Identification of sarilumab pharmacodynamic and predictive markers in patients with inadequate response to TNF inhibition: A biomarker substudy of the phase 3 TARGET study. RMD Open. 2018;4:e000607. https://doi.org/10.1136/rmdopen-2017-000607.

135. Karsdal MA, Schett G, Emery P, et al. IL-6 receptor inhibition positively modulates bone balance in rheumatoid arthritis patients with an inadequate response to anti-tumor necrosis factor therapy: biochemical marker analysis of bone metabolism in the tocilizumab RADIATE study (NCT00106522). Semin Arthritis Rheum. 2012;42:131-9. https://doi. org/10.1016/j.semarthrit.2012.01.004.

136. Garnero P, Thompson E, Woodworth T, et al. Rapid and sustained improvement in bone and cartilage turnover markers with the anti-interleukin-6 receptor inhibitor tocilizumab plus methotrexate in rheumatoid arthritis patients with an inadequate response to methotrexate: results from a substudy of the multicenter double-blind, placebo-controlled trial of tocilizumab in inadequate responders to methotrexate alone. Arthritis Rheum. 2010;62: 33-43. https://doi.org/10.1002/art.25053.

137. Bay-Jensen AC, Platt A, Byrjalsen I, et al. Effect of tocilizumab combined with methotrexate on circulating biomarkers of synovium, cartilage, and bone in the LITHE study. Semin Arthritis Rheum. 2014;43:470-8. https://doi.org/10.1016/j. semarthrit.2013.07.008.

138. Tanaka S, Tanaka Y, Ishiguro N, et al. RANKL: a therapeutic target for bone destruction in rheumatoid arthritis. Mod Rheumatol. 2018;28:9-16. https://doi.org/10.1080/14397595.2017.1369491.

139. Yoshida H, Suzuki M, Tanaka K, et al. Anti-interleukin-6 receptor antibody prevents loss of bone structure and bone strength in collagen-induced arthritis mice. Scand J Rheumatol. 2018;47:384-91. https://doi.org/10.1080/03009742.2017.1416667.

140. Kume K, Amano K, Yamada S, et al. The effect of tocilizumab on bone mineral density in patients with methotrexate-resistant active rheumatoid arthritis. Rheumatology (Oxford). 2014;53:900-3. https://doi.org/10.1093/rheumatology/ket468.

141. Chen YM, Chen HH, Huang WN, et al. Tocilizumab potentially prevents bone loss in patients with anticitrullinated protein antibody-positive rheumatoid arthritis. PLoS ONE. 2017;12:e0188454. https://doi.org/10.1371/journal.pone.0188454.

142. Abu-Shakra M, Zisman D, Balbir-Gurman A, et al. Effect of Tocilizumab on Fatigue and Bone Mineral
Density in Patients with Rheumatoid Arthritis. Isr Med Assoc J. 2018;20:239-44.

143. Fortunet C, Maillefert JF. Comment on: tocilizumab induces corticosteroid sparing in rheumatoid arthritis patients in clinical practice: reply. Rheumatology (Oxford). 2015;54:751-2. https:// doi.org/10.1093/rheumatology/keu468.

144. van Halm VP, Peters MJL, Voskuyl AE, et al. Rheumatoid arthritis versus diabetes as a risk factor for cardiovascular disease: a cross-sectional study, the CARRÉ Investigation. Ann Rheum Dis. 2009;68: 1395. https://doi.org/10.1136/ard.2008.094151.

145. Avina-Zubieta JA, Thomas J, Sadatsafavi M, et al. Risk of incident cardiovascular events in patients with rheumatoid arthritis: a meta-analysis of observational studies. Ann Rheum Dis. 2012;71: 1524-9. https://doi.org/10.1136/annrheumdis2011-200726.

146. Agca R, Heslinga SC, Rollefstad S, et al. EULAR recommendations for cardiovascular disease risk management in patients with rheumatoid arthritis and other forms of inflammatory joint disorders: 2015/2016 update. Ann Rheum Dis. 2017;76:17-28. https://doi.org/10.1136/annrheumdis-2016209775.

147. del Rincon I, Battafarano DF, Restrepo JF, et al. Glucocorticoid dose thresholds associated with allcause and cardiovascular mortality in rheumatoid arthritis. Arthritis Rheumatol. 2014;66:264-72. https://doi.org/10.1002/art.38210.

148. Gonzalez A, Maradit Kremers H, Crowson CS, et al. Do cardiovascular risk factors confer the same risk for cardiovascular outcomes in rheumatoid arthritis patients as in non-rheumatoid arthritis patients? Ann Rheum Dis. 2008;67:64-9. https://doi.org/10. 1136/ard.2006.059980.

149. Salaffi F, Carotti M, Di Carlo M, et al. The Expanded Risk Score in Rheumatoid Arthritis (ERS-RA): performance of a disease-specific calculator in comparison with the traditional prediction scores in the assessment of the 10-year risk of cardiovascular disease in patients with rheumatoid arthritis. Swiss Med Wkly. 2018;148:w14656. https://doi.org/10. 4414/smw.2018.14656.

150. Ridker PM. C-reactive protein: eighty years from discovery to emergence as a major risk marker for cardiovascular disease. Clin Chem. 2009;55:209-15. https://doi.org/10.1373/clinchem.2008.119214.

151. Myasoedova E, Crowson CS, Kremers HM, et al. Lipid paradox in rheumatoid arthritis: the impact of serum lipid measures and systemic inflammation on the risk of cardiovascular disease. Ann Rheum 
Dis. 2011;70:482-7. https://doi.org/10.1136/ard. 2010.135871 .

152. Zhang C, Li X, Niu D, et al. Increased serum levels of beta(2)-GPI-Lp(a) complexes and their association with premature atherosclerosis in patients with rheumatoid arthritis. Clin Chim Acta. 2011;412: 1332-6. https://doi.org/10.1016/j.cca.2011.03.029.

153. Bruun JM, Lihn AS, Verdich C, et al. Regulation of adiponectin by adipose tissue-derived cytokines: in vivo and in vitro investigations in humans. Am J Physiol Endocrinol Metab. 2003;285:E527-533. https://doi.org/10.1152/ajpendo.00110.2003.

154. Di Gregorio GB, Hensley L, Lu T, et al. Lipid and carbohydrate metabolism in mice with a targeted mutation in the IL- 6 gene: absence of development of age-related obesity. Am J Physiol Endocrinol Metab. 2004;287:E182-187. https://doi.org/10. 1152/ajpendo.00189.2003.

155. Trujillo ME, Sullivan S, Harten I, et al. Interleukin-6 regulates human adipose tissue lipid metabolism and leptin production in vitro. J Clin Endocrinol Metab. 2004;89:5577-82. https://doi.org/10.1210/ jc.2004-0603.

156. Saremi A, Anderson RJ, Luo P, et al. Association between IL-6 and the extent of coronary atherosclerosis in the veterans affairs diabetes trial (VADT). Atherosclerosis. 2009;203:610-14. https:// doi.org/10.1016/j.atherosclerosis.2008.07.031.

157. Danesh J, Kaptoge S, Mann AG, et al. Long-term interleukin- 6 levels and subsequent risk of coronary heart disease: two new prospective studies and a systematic review. PLoS Med. 2008;5:e78. https:// doi.org/10.1371/journal.pmed.0050078.

158. Sarwar N, Butterworth AS, Freitag DF, et al. Interleukin-6 receptor pathways in coronary heart disease: a collaborative meta-analysis of 82 studies. Lancet. 2012;379:1205-13. https://doi.org/10.1016/ S0140-6736(11)61931-4.

159. Schultz O, Oberhauser F, Saech J, et al. Effects of inhibition of interleukin-6 signalling on insulin sensitivity and lipoprotein (a) levels in human subjects with rheumatoid diseases. PLoS ONE. 2010;5:e14328. https://doi.org/10.1371/journal. pone.0014328.

160. Kume K, Amano K, Yamada S, et al. Tocilizumab monotherapy reduces arterial stiffness as effectively as etanercept or adalimumab monotherapy in rheumatoid arthritis: an open-label randomized controlled trial. J Rheumatol. 2011;38:2169-71. https://doi.org/10.3899/jrheum.110340.

161. Bacchiega BC, Bacchiega AB, Usnayo MJ, et al. Interleukin 6 Inhibition and Coronary Artery
Disease in a High-Risk Population: A Prospective Community-Based Clinical Study. J Am Heart Assoc 2017;6. DOI: 10.1161/JAHA.116.005038.

162. Giles JT, Sattar N, Gabriel S, et al. Cardiovascular safety of tocilizumab versus etanercept in rheumatoid arthritis: A randomized controlled trial. Aug 30 2019.

163. Fleischmann R, Genovese MC, Lin Y, et al. Longterm safety of sarilumab in rheumatoid arthritis: an integrated analysis with up to 7 years' follow-up. Rheumatology (Oxford). 2020;59:292-302. https:// doi.org/10.1093/rheumatology/kez265.

164. Schiff MH, Kremer JM, Jahreis A, et al. Integrated safety in tocilizumab clinical trials. Arthritis Res Ther. 2011;13:R141. https://doi.org/10.1186/ $\operatorname{ar} 3455$.

165. Maradit-Kremers H, Nicola PJ, Crowson CS, et al. Cardiovascular death in rheumatoid arthritis: a population-based study. Arthritis Rheum. 2005;52: 722-32. https://doi.org/10.1002/art.20878.

166. Bao YK, Weide LG, Ganesan VC, et al. High prevalence of comorbid autoimmune diseases in adults with type 1 diabetes from the HealthFacts database. J Diabetes. 2019;11:273-9. https://doi.org/10.1111/ 1753-0407.12856.

167. Kern PA, Ranganathan S, Li C, et al. Adipose tissue tumor necrosis factor and interleukin- 6 expression in human obesity and insulin resistance. Am J Physiol Endocrinol Metab. 2001;280:E745-E751.

168. Bastard J-P, Maachi M, van Nhieu JT, et al. Adipose tissue IL-6 content correlates with resistance to insulin activation of glucose uptake both in vivo and in vitro. J Clin Endocrinol Metab. 2002;87: 2084-9.

169. Pradhan AD, Manson JE, Rifai N, et al. C-reactive protein, interleukin 6 , and risk of developing type 2 diabetes mellitus. JAMA. 2001;286:327-34.

170. Spranger J, Kroke A, Mohlig M, et al. Inflammatory cytokines and the risk to develop type 2 diabetes: results of the prospective population-based European prospective investigation into cancer and nutrition (EPIC)-Ootsdam study. Diabetes. 2003;52: 812-17.

171. Movahedi M, Beauchamp ME, Abrahamowicz M, et al. Risk of incident diabetes mellitus associated with the dosage and duration of oral glucocorticoid therapy in patients with rheumatoid arthritis. Arthritis Rheumatol. 2016;68:1089-98. https://doi. org/10.1002/art.39537.

172. Eizirik DL, Mandrup-Poulsen T. A choice of death-the signal-transduction of immune-mediated 
beta-cell apoptosis. Diabetologia. 2001;44: 2115-333. https://doi.org/10.1007/s001250100021.

173. Campbell IL, Cutri A, Wilson A, et al. Evidence for IL-6 production by and effects on the pancreatic beta-cell. J Immunol. 1989;143:1188-91.

174. Southern C, Schulster D, Green IC. Inhibition of insulin secretion from rat islets of Langerhans by interleukin-6. An effect distinct from that of interleukin-1. Biochem J. 1990;272:243-5. https://doi. org/10.1042/bj2720243.

175. Genovese MC, Burmester GR, Hagino O, et al. SAT0121 Effect of sarilumab on glycosylated hemoglobin in patients with rheumatoid arthritis and diabetes. Ann Rheum Dis. 2019;78:1128-9. https://doi.org/10.1136/annrheumdis-2019-eular. 3259.

176. Ogata A, Morishima A, Hirano T, et al. Improvement of HbA1c during treatment with humanised anti-interleukin 6 receptor antibody, tocilizumab. Ann Rheum Dis. 2011;70:1164-5. https://doi.org/ 10.1136/ard.2010.132845.

177. Otsuka Y, Kiyohara C, Kashiwado Y, et al. Effects of tumor necrosis factor inhibitors and tocilizumab on the glycosylated hemoglobin levels in patients with rheumatoid arthritis; an observational study. PLoS ONE. 2018;13:e0196368.

178. Murphy LB, Sacks JJ, Brady TJ, et al. Anxiety and depression among US adults with arthritis: prevalence and correlates. Arthritis Care Res (Hoboken). 2012;64:968-76. https://doi.org/10.1002/acr.21685.

179. DiMatteo MR, Lepper HS, Croghan TW. Depression is a risk factor for noncompliance with medical treatment: meta-analysis of the effects of anxiety and depression on patient adherence. Arch Intern Med. 2000;160:2101-7. https://doi.org/10.1001/ archinte.160.14.2101.

180. Lowe B, Willand L, Eich W, et al. Psychiatric comorbidity and work disability in patients with inflammatory rheumatic diseases. Psychosom Med. 2004;66:395-402.

181. Dowlati Y, Herrmann N, Swardfager W, et al. A meta-analysis of cytokines in major depression. Biol Psychiatry. 2010;67:446-57. https://doi.org/10. 1016/j.biopsych.2009.09.033.

182. Haapakoski R, Mathieu J, Ebmeier KP, et al. Cumulative meta-analysis of interleukins 6 and 1beta, tumour necrosis factor alpha and C-reactive protein in patients with major depressive disorder. Brain Behav Immun. 2015;49:206-15. https://doi.org/10. 1016/j.bbi.2015.06.001.
183. Spath-Schwalbe E, Hansen K, Schmidt F, et al. Acute effects of recombinant human interleukin-6 on endocrine and central nervous sleep functions in healthy men. J Clin Endocrinol Metab. 1998;83: 1573-9. https://doi.org/10.1210/jcem.83.5.4795.

184. Virtanen M, Shipley MJ, Batty GD, et al. Interleukin- 6 as a predictor of symptom resolution in psychological distress: a cohort study. Psychol Med. 2015;45:2137-44. https://doi.org/10.1017/ S0033291715000070.

185. Bull SJ, Huezo-Diaz P, Binder EB, et al. Functional polymorphisms in the interleukin- 6 and serotonin transporter genes, and depression and fatigue induced by interferon-alpha and ribavirin treatment. Mol Psychiatry. 2009;14:1095-104. https:// doi.org/10.1038/mp.2008.48.

186. Zhang JC, Yao W, Dong C, et al. Blockade of interleukin- 6 receptor in the periphery promotes rapid and sustained antidepressant actions: a possible role of gut-microbiota-brain axis. Transl Psychiatry. 2017; 7:e1138. https://doi.org/10.1038/tp.2017.112.

187. Mastorakos G and Ilias I. Relationship between interleukin-6 (IL-6) and hypothalamic-pituitaryadrenal axis hormones in rheumatoid arthritis. Z Rheumatol 2000;59(Suppl 2):II/75-79.

188. Jehn CF, Kuhnhardt D, Bartholomae A, et al. Association of IL-6, hypothalamus-pituitary-adrenal axis function, and depression in patients with cancer. Integr Cancer Ther. 2010;9:270-5. https://doi.org/ $10.1177 / 1534735410370036$.

189. Du X, Pang TY. Is dysregulation of the HPA-axis a core pathophysiology mediating co-morbid depression in neurodegenerative diseases? Front Psychiatry. 2015;6:32. https://doi.org/10.3389/ fpsyt.2015.00032.

190. Hong S, Mills PJ, Loredo JS, et al. The association between interleukin-6, sleep, and demographic characteristics. Brain Behav Immun. 2005;19: 165-72. https://doi.org/10.1016/j.bbi.2004.07.008.

191. Burgos I, Richter L, Klein T, et al. Increased nocturnal interleukin- 6 excretion in patients with primary insomnia: a pilot study. Brain Behav Immun. 2006;20:246-53. https://doi.org/10.1016/j.bbi. 2005.06.007.

192. Wittig RM, Zorick FJ, Blumer D, et al. Disturbed sleep in patients complaining of chronic pain. J Nerv Ment Dis. 1982;170:429-31. https://doi.org/ 10.1097/00005053-198207000-00011.

193. Vgontzas AN, Papanicolaou DA, Bixler EO, et al. Circadian interleukin-6 secretion and quantity and depth of sleep. J Clin Endocrinol Metab. 1999;84: 2603-7. https://doi.org/10.1210/jcem.84.8.5894. 
194. Crofford LJ, Kalogeras KT, Mastorakos G, et al. Circadian relationships between interleukin (IL)- 6 and hypothalamic-pituitary-adrenal axis hormones: failure of IL-6 to cause sustained hypercortisolism in patients with early untreated rheumatoid arthritis. J Clin Endocrinol Metab. 1997;82:1279-83. https:// doi.org/10.1210/jcem.82.4.3852.

195. Bazzichi L, Nacci F, Sinigaglia L, et al. Subcutaneous tocilizumab alone or with a csDMARD in rheumatoid arthritis patients: subanalysis of Italian data from a multicenter phase IIIb/IV trial. Clin Rheumatol. 2019;38:841-9. https://doi.org/10. 1007/s10067-018-4327-4.

196. Strand V, Joseph G, van Hoogstraten H, et al. Impact of sarilumab on health related quality of life (HRQoL), fatigue, and sleep in rheumatoid arthritis patients at week 24-results of a phase 3, randomized, double-blind, placebo-controlled, multi-center study. Arthritis Rheumatol. 2014;66:1522.

197. Favalli EG, Desiati F, Atzeni F, et al. Serious infections during anti-TNFalpha treatment in rheumatoid arthritis patients. Autoimmun Rev. 2009;8: 266-73. https://doi.org/10.1016/j.autrev.2008.11. 002.

198. Galloway JB, Hyrich KL, Mercer LK, et al. Anti-TNF therapy is associated with an increased risk of serious infections in patients with rheumatoid arthritis especially in the first 6 months of treatment: updated results from the British Society for Rheumatology Biologics Register with special emphasis on risks in the elderly. Rheumatology (Oxford). 2011;50:124-31. https://doi.org/10.1093/ rheumatology/keq242.

199. Atzeni F, Sarzi-Puttini P, Botsios C, et al. Long-term anti-TNF therapy and the risk of serious infections in a cohort of patients with rheumatoid arthritis: comparison of adalimumab, etanercept and infliximab in the GISEA registry. Autoimmun Rev. 2012;12:225-9. https://doi.org/10.1016/j.autrev. 2012.06.008.

200. Baradat C, Degboe Y, Constantin A, et al. No impact of concomitant methotrexate use on serious adverse event and serious infection risk in patients with rheumatoid arthritis treated with bDMARDs: a systematic literature review and meta-analysis. RMD Open. 2017;3:e000352. https://doi.org/10.1136/ rmdopen-2016-000352.

201. Richter A, Listing J, Schneider M, et al. Impact of treatment with biologic DMARDs on the risk of sepsis or mortality after serious infection in patients with rheumatoid arthritis. Ann Rheum Dis. 2016;75:1667-733. https://doi.org/10.1136/ annrheumdis-2015-207838.
202. Lok LSC, Farahi N, Juss JK, et al. Effects of tocilizumab on neutrophil function and kinetics. Eur J Clin Invest. 2017;47:736-45. https://doi.org/10.1111/ eci.12799.

203. Moots RJ, Sebba A, Rigby W, et al. Effect of tocilizumab on neutrophils in adult patients with rheumatoid arthritis: pooled analysis of data from phase 3 and 4 clinical trials. Rheumatology (Oxford). 2017;56:541-9. https://doi.org/10.1093/ rheumatology/kew370.

204. Emery P, Rondon J, Parrino J, et al. Safety and tolerability of subcutaneous sarilumab and intravenous tocilizumab in patients with rheumatoid arthritis. Rheumatology (Oxford). 2019;58:849-58. https://doi.org/10.1093/rheumatology/key361.

205. Kovalenko P, Paccaly A, Boyapati A, et al. Pharmacodynamic (PD) model of neutrophil margination to describe transient effect of sarilumab on absolute neutrophil count (ANC) in patients with RA after single-dose administration. In: Annual meeting of the population approach group in Europe 2017, p. 26.

206. Askling J, Fored CM, Brandt L, et al. Risks of solid cancers in patients with rheumatoid arthritis and after treatment with tumour necrosis factor antagonists. Ann Rheum Dis. 2005;64:1421-6. https:// doi.org/10.1136/ard.2004.033993.

207. Askling J, Fored CM, Baecklund E, et al. Haematopoietic malignancies in rheumatoid arthritis: lymphoma risk and characteristics after exposure to tumour necrosis factor antagonists. Ann Rheum Dis. 2005;64:1414-20. https://doi.org/10.1136/ard. 2004.033241.

208. Smitten AL, Simon TA, Hochberg MC, et al. A metaanalysis of the incidence of malignancy in adult patients with rheumatoid arthritis. Arthritis Res Ther. 2008;10:R45. https://doi.org/10.1186/ar2404.

209. Lippitz BE. Cytokine patterns in patients with cancer: a systematic review. Lancet Oncol. 2013;14: e218-228. https://doi.org/10.1016/S14702045(12)70582-X.

210. Hirano T, Ishihara K, Hibi M. Roles of STAT3 in mediating the cell growth, differentiation and survival signals relayed through the IL- 6 family of cytokine receptors. Oncogene. 2000;19:2548-56. https://doi.org/10.1038/sj.onc.1203551.

211. Bergmann J, Muller M, Baumann N, et al. IL-6 transsignaling is essential for the development of hepatocellular carcinoma in mice. Hepatology. 2017;65: 89-103. https://doi.org/10.1002/hep.28874.

212. Harmer D, Falank C, Reagan MR. Interleukin-6 Interweaves the Bone Marrow Microenvironment, 
Bone Loss, and Multiple Myeloma. Front Endocrinol (Lausanne). 2018;9:788. https://doi.org/10. 3389/fendo.2018.00788.

213. Chong PSY, Chng WJ and de Mel S. STAT3: A Promising Therapeutic Target in Multiple Myeloma. Cancers (Basel). 2019;11. DOI: 10. 3390/cancers11050731.

214. Chonov DC, Ignatova MMK, Ananiev JR, et al. IL-6 Activities in the Tumour Microenvironment. Part 1. Open Access Maced J Med Sci. 2019;7:2391-2398. DOI: $10.3889 /$ oamjms.2019.589.

215. Zhang J, Chu M. Targeting of IL-6-relevant long noncoding RNA profiles in inflammatory and tumorous disease. Inflammation. 2019;42:1139-46. https://doi.org/10.1007/s10753-019-00995-2.

216. Genovese MC, Rubbert-Roth A, Smolen JS, et al. Longterm safety and efficacy of tocilizumab in patients with rheumatoid arthritis: a cumulative analysis of up to 4.6 years of exposure. J Rheumatol. 2013;40:768-80. https://doi.org/10.3899/jrheum. 120687.

217. Wolfe F, Michaud K. Biologic treatment of rheumatoid arthritis and the risk of malignancy: analyses from a large US observational study. Arthritis Rheum. 2007;56:2886-955. https://doi. org/10.1002/art.22864.

218. Sparks JA, He X, Huang J, et al. Rheumatoid arthritis disease activity predicting incident clinically apparent rheumatoid arthritis-associated interstitial lung disease: a prospective cohort study. Arthritis Rheumatol. 2019;71:1472-82. https://doi.org/10. 1002/art.40904.

219. De Lauretis A, Sestini P, Pantelidis P, et al. Serum interleukin 6 is predictive of early functional decline and mortality in interstitial lung disease associated with systemic sclerosis. J Rheumatol. 2013;40:435-46. https://doi.org/10.3899/jrheum. 120725.

220. Matsuo T, Hashimoto M, Ito I, et al. Interleukin-18 is associated with the presence of interstitial lung disease in rheumatoid arthritis: a cross-sectional study. Scand J Rheumatol. 2019;48:87-94. https:// doi.org/10.1080/03009742.2018.1477989.

221. Picchianti Diamanti A, Germano V, Bizzi E, et al. Interstitial lung disease in rheumatoid arthritis in the era of biologics. Pulm Med 2011. Epub ahead of print Nov 10. DOI: 10.1155/2011/931342.

222. Mohr M, Jacobi A. Interstitial lung disease in rheumatoid arthritis: response to IL-6R blockade. Scand J Rheumatol. 2011;40:400.
223. Khanna D, Denton CP, Jahreis A, et al. Safety and efficacy of subcutaneous tocilizumab in adults with systemic sclerosis (faSScinate): a phase 2, randomised, controlled trial. Lancet. 2016;387: 2630-40. https://doi.org/10.1016/S01406736(16)00232-4.

224. Narvaez J, Mora-Liminana M, Ros I, et al. Pulmonary arterial hypertension in adult-onset Still's disease: A case series and systematic review of the literature. Semin Arthritis Rheum. 2019;49:162-70. https://doi.org/10.1016/j.semarthrit.2018.11.007.

225. Picchianti Diamanti A, Markovic M, Argento G, et al. Therapeutic management of patients with rheumatoid arthritis and associated interstitial lung disease: case report and literature review. Ther Adv Respir Dis. 2017;11:64-72. https://doi.org/10.1177/ 1753465816668780 .

226. Manfredi A, Sebastiani M, Cassone G, et al. Tocilizumab for the treatment of patients with rheumatoid arthritis and interstitial lung diseases: a case series. Clin Exp Rheumatol. 2018;36:342.

227. Otsuji N, Sugiyama K, Nakano K, et al. Effect of tocilizumab on interstitial lung disease in patients with rheumatoid arthritis. Respirology. 2018;23:78.

228. Gibofsky A, Galloway J, Kekow J, et al. Comparison of patient and physician perspectives in the management of rheumatoid arthritis: results from global physician- and patient-based surveys. Health Qual Life Outcomes. 2018;16:211. https://doi.org/10. 1186/s12955-018-1035-3.

229. van Hulst LT, Kievit W, van Bommel R, et al. Rheumatoid arthritis patients and rheumatologists approach the decision to escalate care differently: results of a maximum difference scaling experiment. Arthritis Care Res (Hoboken). 2011;63: 1407-14. https://doi.org/10.1002/acr.20551.

230. Strand V, Kosinski M, Graham N, et al. Impact of sarilumab on fatigue, pain, morning stiffness, productivity, and health related quality of life (HRQOL) in patients with active rheumatoid arthritis who were inadequate responders or intolerant of antiTNF-a therapy: results from a Phase 3 study (RCT). Arthritis Rheumatol. 2015;67(Suppl 10):625-6.

231. Hsiao B, Fraenkel L. Patient preferences for rheumatoid arthritis treatment. Curr Opin Rheumatol. 2019;31:256-63. https://doi.org/10. 1097/bor.0000000000000591.

232. Kivitz A, Baret-Cormel L, van Hoogstraten H, et al. Usability and patient preference phase 3 study of the sarilumab pen in patients with active moderateto-severe rheumatoid arthritis. Rheumatol Ther. 2018;5:231-42. https://doi.org/10.1007/s40744017-0090-2. 
233. Crotti C, Biggioggero M, Becciolini A, et al. Sarilumab: patient-reported outcomes in rheumatoid arthritis. Patient Relat Outcome Meas. 2018;9: 275-84. https://doi.org/10.2147/prom.S147286.

234. Strand V, Mangan E, Hagino O, et al. Exploring the effects of depressive symptoms on the efficacy of sarilumab and improvements in health-related quality of life. Arthritis Rheumatol. 2018;70(Suppl 9):1709-11.

235. Figueiredo-Braga M, Cornaby C, Cortez A, et al. Influence of biological therapeutics, cytokines, and disease activity on depression in rheumatoid arthritis. J Immunol Res 2018. Epub ahead of print Jul 17. DOI: $10.1155 / 2018 / 5954897$.

236. Strand V, Kosinski M, Chen CI, et al. Sarilumab plus methotrexate improves patient-reported outcomes in patients with active rheumatoid arthritis and inadequate responses to methotrexate: results of a phase III trial. Arthritis Res Ther. 2016;18:198. https://doi.org/10.1186/s13075-016-1096-9.

237. Strand V, Reaney M, Chen CI, et al. Sarilumab improves patient-reported outcomes in rheumatoid arthritis patients with inadequate response/intolerance to tumour necrosis factor inhibitors. RMD Open. 2017;3:e000416. https://doi.org/10.1136/ rmdopen-2016-000416.

238. Gossec L, Boklage S, St John G, et al. Pain is improved in around $50 \%$ of patients and fatigue in $40 \%$ of patients with rheumatoid arthritis treated with sarilumab in the target, mobility and monarch trials. In: Arthritis and Rheumatology 2018, Wiley.

239. Burmester GR, Feist E, Kellner H, et al. Effectiveness and safety of the interleukin 6-receptor antagonist tocilizumab after 4 and 24 weeks in patients with active rheumatoid arthritis: the first phase IIIb reallife study (TAMARA). Ann Rheum Dis. 2011;70: 755-9. https://doi.org/10.1136/ard.2010.139725.

240. Strand V, Gossec L, Proudfoot CWJ, et al. Patientreported outcomes from a randomized phase III trial of sarilumab monotherapy versus adalimumab monotherapy in patients with rheumatoid arthritis. Arthritis Res Ther. 2018;20:129. https://doi.org/10. 1186/s13075-018-1614-z.

241. Gossec L, Strand V, Proudfoot C, et al. Effects of sarilumab on rheumatoid arthritis as reported by patients using the rheumatoid arthritis impact of disease scale. J Rheumatol. 2019;46:1259-67. https://doi.org/10.3899/jrheum.180904.

242. Strand V, Michalska M, Birchwood C, et al. Impact of tocilizumab monotherapy on patient-reported outcomes in patients with rheumatoid arthritis from two randomised controlled trials. RMD Open. 2017;3:e000496. https://doi.org/10.1136/rmdopen2017-000496.

243. Mohan S, Michalska M, Yourish J, et al. OP0105 Long-term safety of tocilizumab from large clinical trial and postmarketing populations. Ann Rheum Dis. 2017;76:95. https://doi.org/10.1136/ annrheumdis-2017-eular.3573.

244. Grøn KL, Glintborg B, Nørgaard M, et al. Overall infection risk in rheumatoid arthritis during treatment with abatacept, rituximab and tocilizumab; an observational cohort study. Rheumatology (Oxford). 2019:kez530. DOI: 10.1093/rheumatology/ kez530.

245. Grøn KL, Arkema EV, Glintborg B, et al. Risk of serious infections in patients with rheumatoid arthritis treated in routine care with abatacept, rituximab and tocilizumab in Denmark and Sweden. Ann Rheum Dis. 2019;78:320-7. https://doi. org/10.1136/annrheumdis-2018-214326.

246. Rutherford AI, Subesinghe S, Hyrich KL, et al. Serious infection across biologic-treated patients with rheumatoid arthritis: Results from the British Society for Rheumatology biologics register for rheumatoid arthritis. Ann Rheum Dis. 2018;77: 905-10. https://doi.org/10.1136/annrheumdis2017-212825.

247. Iannone F, Ferraccioli G, Sinigaglia L, et al. Realworld experience of tocilizumab in rheumatoid arthritis: Sub-analysis of data from the Italian biologics' register GISEA. Clin Rheumatol. 2018;37: 315-21. https://doi.org/10.1007/s10067-017-38468.

248. Sakai R, Cho S, Nanki T, et al. Head-to-head comparison of the safety of tocilizumab and tumor necrosis factor inhibitors in rheumatoid arthritis patients (RA) in clinical practice: Results from the registry of Japanese RA patients on biologics for long-term safety (REAL) registry. Arthritis Res Ther. 2015;23:74. https://doi.org/10.1186/s13075-0150583-8.

249. Atsumi T, Fujio K, Yamaoka K, et al. Safety and effectiveness of subcutaneous tocilizumab in patients with rheumatoid arthritis in a real-world clinical setting. Mod Rheumatol. 2018;28:780-8. https://doi.org/10.1080/14397595.2017.1416760.

250. Gavazzi G, Krause K-H. Ageing and infection. Lancet Infect Dis. 2002;2:659-66.

251. Martis N, Chirio D, Queyrel-Moranne V, et al. Tocilizumab-induced hypofibrinogenemia: a report of 7 cases. Joint Bone Spine. 2017;84:369-70. https://doi.org/10.1016/j.jbspin.2016.04.008. 
252. Schaeverbeke T, Truchetet ME, Kostine M, et al. Immunogenicity of biologic agents in rheumatoid arthritis patients: lessons for clinical practice. Rheumatology (Oxford). 2016;55:210-20. https:// doi.org/10.1093/rheumatology/kev277.

253. Tabata S, Higuchi T, Tatsukawa S, et al. Idiopathic multicentric Castleman disease with autoimmune hemolytic anemia and production of anti-drug antibody against tocilizumab: A case report. Intern
Med. 2019;58:3313-18. DOI: 10.2169/internalmedicine.2989-19.

254. Wells AF, Parrino J, Mangan EK, et al. Immunogenicity of sarilumab monotherapy in patients with rheumatoid arthritis who were inadequate responders or intolerant to disease-modifying antirheumatic drugs. Rheumatol Ther. 2019;6:339-52. https://doi.org/10.1007/s40744-019-0157-3. 